\title{
Properties of a Distinct Subpopulation of GABAergic Commissural Interneurons That Are Part of the Locomotor Circuitry in the Neonatal Spinal Cord
}

\author{
Linying Wu, ${ }^{1}$ Patrick M. Sonner, ${ }^{2}$ David J. Titus, ${ }^{1}$ Erik P. Wiesner, ${ }^{1}$ Francisco J. Alvarez, ${ }^{2}$ and Lea Ziskind-Conhaim ${ }^{1}$ \\ ${ }^{1}$ Department of Physiology and Center for Neuroscience, School of Medicine and Public Health, University of Wisconsin, Madison, Wisconsin 53706, and \\ 2Department of Neuroscience, Cell Biology, and Physiology, Wright State University, Dayton, Ohio 45435
}

\begin{abstract}
Commissural inhibitory interneurons (INs) are integral components of the locomotor circuitry that coordinate left-right motor activity during movements. We have shown that GABA-mediated synaptic transmission plays a key role in generating alternating locomotor-like activity in the mouse spinal cord (Hinckley et al., 2005a). The primary objective of our study was to determine whether properties of lamina VIII (LVIII) GABAergic INs in the spinal cord of GAD67::GFP transgenic mice fit the classification of rhythm-coordinating neurons in the locomotor circuitry. The relatively large green fluorescent protein-expressing $\left(\mathrm{GFP}^{+}\right) \mathrm{INs}$ had comparable morphological and electrophysiological properties, suggesting that they comprised a homogenous neuronal population. They displayed multipolar and complex dendritic arbors in ipsilateral LVII-LVIII, and their axonal projections crossed the ventral commissure and branched into contralateral ventral, medial, and dorsal laminae. Putative synaptic contacts evident as bouton-like varicosities were detected in close apposition to lateral motoneurons, Renshaw cells, other $\mathrm{GFP}^{+}$INs, and unidentified neurons. Exposure to a rhythmogenic mixture triggered locomotor-like rhythmic firing in the majority of LVIII GFP ${ }^{+}$INs. Their induced oscillatory activity was out-of-phase with bursts of contralateral motoneurons and in-phase with bouts of ipsilateral motor activity. Membrane voltage oscillations were elicited by rhythmic increases in excitatory synaptic drive and might have been augmented by three types of voltage-activated cationic currents known to increase neuronal excitability. Based on their axonal projections and activity pattern, we propose that this population of GABAergic INs forms a class of local commissural inhibitory interneurons that are integral component of the locomotor circuitry.
\end{abstract}

\section{Introduction}

In all walking vertebrates, left-right limb movements are controlled by spinal networks that are referred to as the locomotor central pattern generators (CPGs) (Pearson, 1993; Jankowska, 2001; Kiehn and Kullander, 2004; Grillner, 2006). The mammalian CPG can function autonomously, and its fundamental organization includes ipsilateral rhythmogenic interneurons (INs) that control the timing of rhythmic motor activity and layers of interneuronal circuits that pattern the motor output and control the selection of motor synergies adapted to different types of movement (Endo and Kiehn, 2008) (for review, see McCrea and Rybak, 2008). Among these, there are populations of commissural interneurons (CINs) whose axons terminate in the contralateral side and coordinate motor activity between the left and right sides of the spinal cord. To dissect the functional organization of different subclasses of CINs, it is essential to examine their cellular properties, target connections, and firing patterns during different phases of the step cycle. These criteria have been applied

\footnotetext{
Received Sept. 10, 2010; revised Nov. 1, 2010; accepted Jan. 20, 2011.

This study was supported by National Institutes of Health Grants NS047357 (F.J.A.) and NS23808 (L.Z.-C..). We thank Dr. Robert Conhaim and William Dovi for help with confocal imaging of GABA immunoreactivity and Dr. Yakov Verbny and William Mustas for help with illustrations.

Correspondence should be addressed to Lea Ziskind-Conhaim, Department of Physiology, 129 SMI, 1300 University Avenue, University of Wisconsin, Madison, WI 53706. E-mail: Iziskind@.wisc.edu.

DOI:10.1523/JNEUROSCI.4764-10.2011

Copyright $\odot 2011$ the authors $\quad 0270-6474 / 11 / 314821-13 \$ 15.00 / 0$
}

to identify various groups of CINs with different functions in the adult cat spinal cord (for review, see Jankowska, 2008). Similar studies have been conducted using the neonatal rodent spinal cord, a suitable preparation for intracellular electrophysiological recording during fictive locomotor activity and morphological analyses of neuronal projections. Two major groups of commissural inhibitory interneurons that are probably involved in leftright alternating motor activity have been described in the lumbar spinal cord of rodents and cats: short-range segmental CINs and long-range CINs with rostral, caudal, or bifurcate projections that extend beyond their segmental levels (Butt et al., 2002; Stokke et al., 2002; Birinyi et al., 2003; Jankowska et al., 2003, 2005; Hammar et al., 2004; Matsuyama et al., 2004, 2006; Carlin et al., 2006; Quinlan and Kiehn, 2007). Different combinations of glutamatergic, glycinergic, and GABAergic interneurons have been identified within these groups. In addition the cellular properties, synaptic inputs onto premotor interneurons and motoneurons, and locomotor-like rhythmic activity also differ among populations of CINs with long-range caudally or rostrally projecting axons (Butt and Kiehn 2003; Zhong et al., $2006 a, b, 2007)$. At present, there is scant information about local CINs with relatively short axonal projections that arborize within the same segment or adjacent rostral or caudal segments.

We have reported previously that GABAergic transmission regulates the onset and duration of alternating left-right locomotor-like rhythmic motor activity in the neonatal mouse 
spinal cord (Hinckley et al., 2005a), but not much is known about the groups of GABAergic CINs that provide rhythmic inhibitory inputs to the contralateral side of the cord. In this study, we describe a subpopulation of GABAergic CINs in one line of GAD67::GFP transgenic mice (Oliva et al., 2000) known to express green fluorescent protein (GFP) only in discrete subpopulations of GAD67 interneurons. The objective of our study was to examine whether properties of lamina VIII (LVIII) GFP-expressing $\left(\mathrm{GFP}^{+}\right)$neurons in this mouse line match the classification of neurons integrated in commissural networks coordinating the left-right alternating rhythms in the neonatal spinal cord.

Parts of this work have been published previously in abstract form (Wu and Ziskind-Conhaim, 2006).
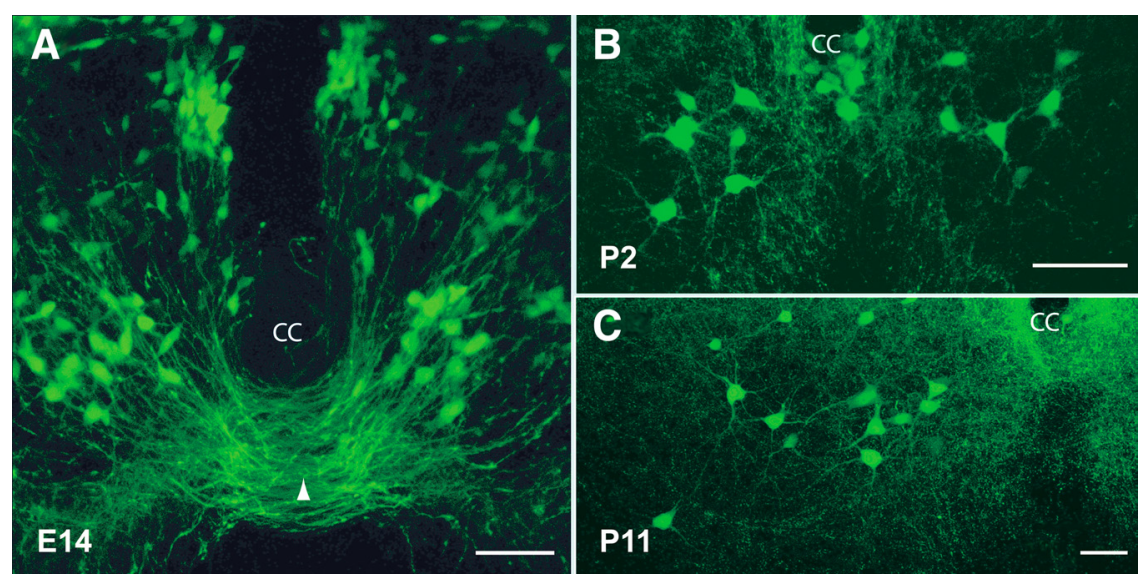

Figure 1. The number of ventral GFP ${ }^{+}$INs decreased significantly during prenatal development. $\boldsymbol{A}$, Numerous small INs that extended a limited number of neurites were located ventromedially at E14. These neurons send abundant GFP ${ }^{+}$projections that crossed the midline (arrowhead). B, Significantly fewer but larger INs were observed after birth (P2). C, A similar pattern was observed in juvenile mice (P11). Postnatal GFP ${ }^{+}$INs had multipolar dendritic arborizations, and some were distributed right along the midline. The images are superimpositions of 35-42 confocal optical sections obtained with $0.5 \mu \mathrm{m} Z$-steps. CC, Central canal. Scale bars: $\boldsymbol{A}, 50 \mu \mathrm{m} ; \boldsymbol{B}, \boldsymbol{C}, 100 \mu \mathrm{m}$.

\section{Materials and Methods}

The GAD67::GFP mouse [FVB-Tg(GadGFP)45704Swn/J], also known as the GIN mice, was generated originally in the laboratory of Dr. John W. Swann (Baylor College of Medicine, Houston, TX) (Oliva et al., 2000). We obtained it from The Jackson Laboratory (stock\#003718), and the mice used in the study were bred at our facility. In these transgenic mice, the upstream regulatory sequence from the murine Gadl gene is used to control the expression of enhanced green fluorescence protein (eGFP) and results in labeling of some subpopulations of GABAergic interneurons in the cortex (Oliva et al., 2000) and a significant proportion of GABAergic interneurons in the spinal cord, as assessed by combined immunocytochemical staining of GABA-immunoreactive (IR) cells (Dougherty et al., 2009).

Ventral root and whole-cell patch-clamp recordings. Newborn, postnatal day 1 (P1) to P4 female and male mice were anesthetized by hypothermia. After decapitation, the spinal cord with ventral roots T12-S2 attached was extracted in ice-cold oxygenated extracellular solution (see composition below). Two different preparations were used in this study. Thick $(300-400 \mu \mathrm{m})$ transverse tissue slices obtained with a vibratome (VT1000S; Leica) were prepared to analyze the firing properties and axonal projections of LVIII GFP ${ }^{+}$INs in segments L1-L3. A second preparation was used to simultaneously record the firing patterns in $\mathrm{GFP}^{+}$INs and ventral roots during induced locomotor-like rhythmic activity. In those experiments, the spinal cord was sliced longitudinally in a plane slightly lateral to the midline to expose the LVIII GFP ${ }^{+}$neurons. This cut produced two hemicords: a large cord with part of LVIII and the contralateral side of the spinal cord with its ventral roots attached and a small cord with part of LVIII and the rest of the ipsilateral spinal cord with the ventral roots. The two asymmetric cords were placed in the recording chamber with the medial side up so that GFP ${ }^{+}$INs could be targeted for whole-cell patch-clamp recordings. In the large hemicord, activity in $\mathrm{GFP}^{+}$INs was correlated with bursts in contralateral ventral roots, whereas firing of GFP ${ }^{+}$INs in the complementary, smaller hemicord was correlated with activity in ipsilateral ventral roots.

The isolated hemicords or the transverse spinal cord slices were equilibrated at room temperature for $30 \mathrm{~min}$ and then transferred to the recording chamber, in which they were superfused with oxygenated extracellular solution at room temperature. Motor activity was monitored in hemicords by drawing ventral roots of upper lumbar segments (L1L3) into tight-fitting, recording suction pipettes (Hinckley et al., 2005a, 2010). Ventral root electroneurograms were filtered between $300 \mathrm{~Hz}$ and $1-3 \mathrm{kHz}$ and acquired at a sampling rate of $10 \mathrm{kHz}$. Locomotor-like voltage membrane oscillations were produced by a rhythmogenic mixture that included $N$-methyl-DL-aspartic acid (NMA) (5 $\mu \mathrm{M}$ ), 5-hydroxytryptamine creatinine sulfate complex (serotonin) (10 $\mu \mathrm{M})$, and dopamine (50 $\mu \mathrm{M})$ (Hinckley et al., 2005b).

Whole-cell patch pipettes were targeted to $\mathrm{GFP}^{+}$cells using an epifluorescence microscope (BX50WI; Olympus) equipped with a $475 \mathrm{~nm}$ excitation filter, a $505 \mathrm{~nm}$ dichroic mirror, and a $535 \mathrm{~nm}$ emission filter (Omega Optics). Electrode tip resistance ranged from 5 to $7 \mathrm{M} \Omega$ (P-97 multistage puller; Sutter Instruments). Intracellular potentials/currents were filtered at $3 \mathrm{kHz}$, sampled at $10-20 \mathrm{kHz}$ (Multiclamp 700B amplifier; Molecular Devices), and recorded on a personal computer with Clampex software (version 9.2). Membrane potentials were corrected for a $10 \mathrm{mV}$ liquid junction potential (Gao et al., 2001).

Morphological and immunohistochemical analyses of $\mathrm{GFP}^{+} I N$ s. The spinal cords of P1-P4 neonates and embryonic day 14 (E14) embryos were removed and fixed "en bloc" in $4 \%$ paraformaldehyde in $0.01 \mathrm{M}$ PBS, pH 7.4, overnight. Transverse slices $(70 \mu \mathrm{m})$ were obtained to study the location of $\mathrm{GFP}^{+}$cells. Immunohistochemistry for GABA was performed in histological spinal cord sections from P1-P4 neonates. Freefloating slices were rinsed with $0.01 \mathrm{M}$ PBS containing $0.1 \%$ Triton X-100 (TX) (30 min) and blocked with donkey serum (10\% in $0.01 \mathrm{M}$ PBS with $0.1 \% \mathrm{TX}$ ) for $90 \mathrm{~min}$. The slices were then incubated in primary antisera overnight $\left(4^{\circ} \mathrm{C}\right)$ using antibodies against GABA (1:2000, rabbit polyclonal; Sigma) combined in most cases with antibodies against GFP (1: 500 , goat polyclonal, FITC conjugated; Abcam). Slices were then rinsed in $0.01 \mathrm{M}$ PBS and incubated for $3-5 \mathrm{~h}$ in secondary antibodies against rabbit IgGs conjugated to cyanine 3 (Cy3) (1:100-1:500; The Jackson Laboratory) for detection of GABA immunoreactivity. After secondary antibody incubations, the sections were washed in PBS, mounted on glass slides, and coverslipped using Vectashield. Slices were imaged at low $(10 \times 1)$ and medium $(20 \times 1-1.5)$ magnifications using Bio-Rad MRC1024ES confocal microscope.

The morphological characteristics of $\mathrm{GFP}^{+}$INs were examined after Neurobiotin filling during intracellular recording using electrodes that contained $0.5-0.7 \%$ Neurobiotin. Intracellular labeling was performed in either the longitudinally hemisected spinal cord during induced locomotor activity (Ziskind-Conhaim et al., 2008) or thick transverse slices. The transverse orientation was greatly advantageous to map axonal projections in the contralateral side. At the end of the recording session, the preparations were fixed overnight in $4 \%$ paraformaldehyde in $0.1 \mathrm{M}$ PBS, $\mathrm{pH}$ 7.4. Transverse thick slices that contained Neurobiotin-filled GFP ${ }^{+}$ INs were processed without further resectioning. Neurobiotin-filled cells were revealed with Alexa Fluor 555-coupled to streptavidin (1:50; Invitrogen). The slices were then rinsed with $0.01 \mathrm{~m}$ PBS and blocked with normal donkey serum ( $10 \%$ in $0.01 \mathrm{M}$ PBS with $0.1 \%$ TX) for $45 \mathrm{~min}$. They were then incubated, free-floating, in primary antisera for $3 \mathrm{~d}\left(4^{\circ} \mathrm{C}\right)$ 

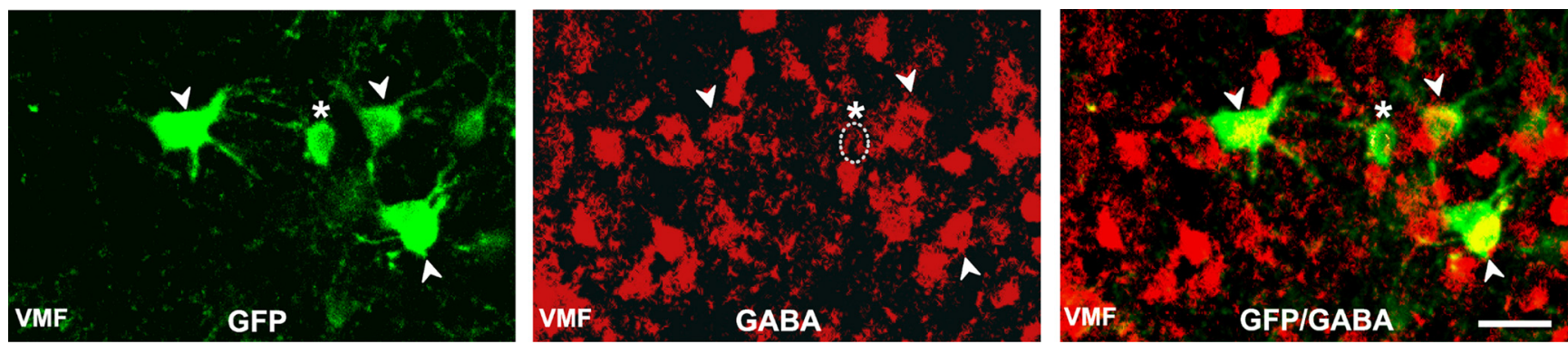

Figure 2. GABA immunoreactivity in LVIII GFP ${ }^{+}$INs. GABA expression was observed in three (arrowheads) or possibly four (asterisk and dotted ring) of the six GFP ${ }^{+}$INs in this field of LVIII. GFP ${ }^{+}$INs constituted only a small fraction of GABA-IR INs. The projected image consists of seven confocal optical sections ( $2 \mu \mathrm{m} Z$-steps). VMF, Ventromedial funiculus. Medial is down, and central canal is to the right. Scale bar, $50 \mu \mathrm{m}$.
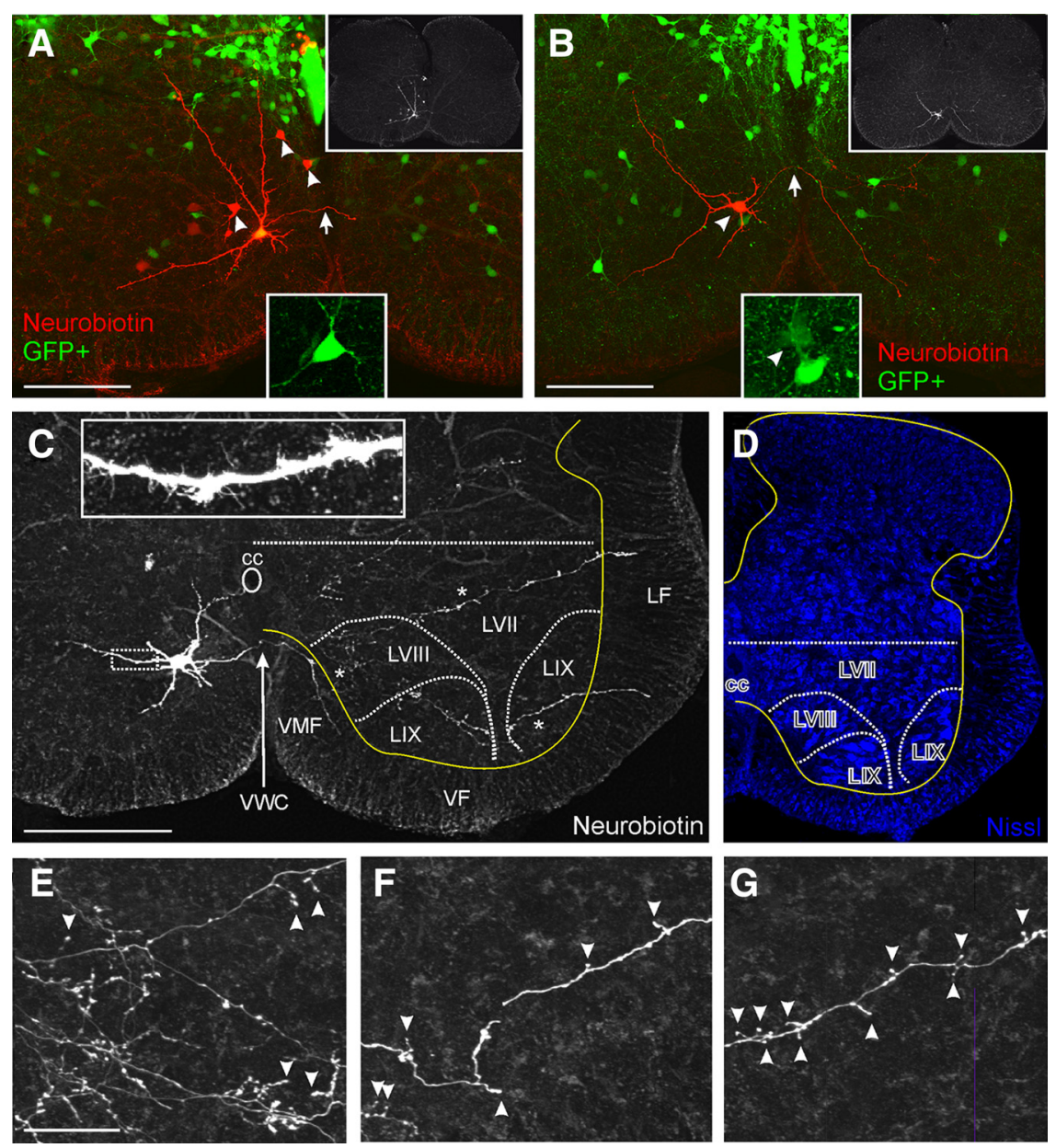

Figure 3. Morphology of commissural GFP ${ }^{+}$INs in the lumbar spinal cord. $A, B$, Examples of GFP ${ }^{+}$cells (green, GFP, shown in bottom insets) targeted for electrophysiological recordings and filled with Neurobiotin (red, streptavidin 555). The somata were located in LVIII (shown in top right corner insets within the whole spinal cord) and were multipolar, extending dendritic arbors extensively into ipsilateral LVII and LVIII. The axons (arrows) usually emerged from the cell body, ascended toward the central canal, crossed the midline, and extended branches contralaterally. In $A$, several cell bodies were more weakly labeled with Neurobiotin (arrowheads), suggesting gap-junctional coupling with the recorded cell. Interestingly, none of the Neurobiotin-coupled cells was GFP ${ }^{+}$. C, A relatively complete example of an LVIII Neurobiotin-filled GFP ${ }^{+}$neuron. Inset, High-magnification image (from region inside dashed box) of dendritic filopodia, suggesting ongoing synaptogenesis. Neurobiotin filling is shown in black and white to provide a better resolution of fine branches in the contralaterally projecting axon. Laminar boundaries (dashed white lines), position of the central canal (cc) and ventral white commissure (VWC), and the border between gray and white matter (continuous yellow line) are superimposed from theNisslimage (Alexa Fluor 405-Nissl) of this same spinal cord section shown in $\boldsymbol{D}$ (blue). The axon crossed in the ventral white commissure (VWC) and then turned into the ventromedia funiculus from where it branched three different collaterals that crossed the spinal cord in slightly different directions. These branches eventually entered the lateral funiculus (LF) at different dorsoventral points. One branch projected dorsolaterally into the dorsal horn, another laterally through LVIII and into LVII, whereas the last one projected ventrolaterally through LVIII, into medial LIX, ventral LVII, and then into lateral LIX. All three collaterals left terminal arborizations and en passant boutons as they traversed the spinal cord. The regions marked with asterisks are enlarged in $\boldsymbol{E}-\mathbf{G}$. $\boldsymbol{E}-\boldsymbol{G}$, Medium-magnification images of putative synaptic varicosities (arrowheads) in LVIII (E), LIX $(\boldsymbol{F})$, and dorsal LVII (G). Synaptic varicosities and terminal arborizations were denser in medial LVII than in other laminae. Scale bars: $A$, $\boldsymbol{B}, 150 \mu \mathrm{m} ; \boldsymbol{C}, 200 ; \boldsymbol{E}, 50 \mu \mathrm{m}$ ( $\boldsymbol{F}$ and $\boldsymbol{G}$ are at the same magnification). using antibodies against GFP (1:500, sheep polyclonal; AbD Serotec) combined with antibodies against either calbindin (CB) (1:500, rabbit polyclonal; Swant) or choline acetyl transferase (ChAT) (1:200, goat polyclonal; Millipore). After the exposure to primary antisera, slices were rinsed in $0.01 \mathrm{M}$ PBS and incubated for $6 \mathrm{~h}$ at room temperature in fluorescent-conjugated secondary antibodies. GFP was visualized with FITC-conjugated secondary antibodies (1:100; Jackson ImmunoResearch), whereas calbindin immunoreactivity and ChAT-IR neurons were detected with Cy5-conjugated secondary antibodies (1:50; Jackson ImmunoResearch). To establish laminar boundaries, all sections were counterstained with a blue fluorescent Nissl (Neurotrace 435/455; diluted 1:100; Invitrogen). All primary and secondary antisera were diluted in $0.01 \mathrm{M}$ PBS with $0.1 \% \mathrm{TX}$. Slices were rinsed a final time in $0.01 \mathrm{M}$ PBS and mounted on glass slides with the Neurobiotinlabeled cells positioned on the top surface of the thick slice. The sections were then coverslipped with Vectashield (Vector Laboratories) and imaged using an Olympus FV1000 confocal microscope.

Hemisected spinal cords containing Neurobiotin-filled $\mathrm{GFP}^{+}$INs were washed after fixation, embedded in $4-5 \%$ agar, and cut into transverse $70 \mu \mathrm{m}$ sections. The resulting sections were then incubated for $3-5 \mathrm{~h}$ in avidin-rhodamine (1:1000; Jackson ImmunoResearch) in PBS containing $0.3 \%$ TX. After the final rinse in PBS, slices were mounted in serial order on glass slides and coverslipped with Vectashield.

Data analysis. Electrophysiological properties of $\mathrm{GFP}^{+}$INs were analyzed in neurons held at $-60 \mathrm{mV}$. Hyperpolarization-activated depolarization sag is one of the hallmarks of these neurons; therefore, only neurons that generate the depolarization sags were included in the analysis. Input resistance was calculated based on the averaged hyperpolarizations generated by steps of negative currents that did not produce hyperpolarization-activated depolarization sags. Membrane capacitance was estimated from the membrane time constant. The rheobase was defined as the minimal current required for action potential generation. Action potential threshold was established at the voltage with rate of rise $>20 \mathrm{~V} / \mathrm{s}$. Action potential half-width was measured at the potential 
halfway from threshold to the peak of the action potential. The afterhyperpolarization (AHP) was estimated from the action potential threshold to the peak negative voltage after the action potential.

Properties of motor activity were typically analyzed offline from samples of 20 successive rhythmic bursts (Hinckley et al., 2005a). To facilitate the analysis of burst properties, extracellular recordings were rectified and smoothed using adjacent averaging over $100-$ 300 points (Origin 6; MicroCal). These were used to calculate the cycle period and burst interval, duration, and amplitude. Cycle period was defined as the time between the onset of two consecutive bursts, and burst duration was measured as the time between the onset of excitation and its return to baseline. Paired $t$ tests were used to determine the statistical significance $(p<0.05)$, and data are expressed as mean \pm SE.

Solutions and chemicals. Extracellular solution contained the following (in $\mathrm{mm}$ ): 128 $\mathrm{NaCl}, 4 \mathrm{KCl}, 1.5 \mathrm{CaCl}_{2}, 1 \mathrm{MgSO}_{4}, 0.5$ $\mathrm{NaH}_{2} \mathrm{PO}_{4}, 21 \mathrm{NaHCO}_{3}$, and 30 glucose. The solution was adjusted to $\mathrm{pH} 7.3$ using $\mathrm{NaOH}$, and the osmolarity was $315-325 \mathrm{mOsm}$. The whole-cell pipette solution contained the following (in $\mathrm{mm}$ ): $140 \mathrm{~K}$-gluconate, $9 \mathrm{KCl}, 10$ HEPES, 0.2 EGTA, $1 \mathrm{Mg}$-ATP, and 0.1 GTP. The solution was adjusted to $\mathrm{pH} 7.2$ using $\mathrm{KOH}$, and the osmolarity was $290-305 \mathrm{mOsm}$. All chemicals were obtained from Sigma.

\section{Results}

Morphological characterization of LVIII GFP ${ }^{+}$interneurons

The majority of $\mathrm{GFP}^{+}$INs in the neonatal spinal cord of GAD67::GFP mice were broadly distributed in the dorsal horn and intermediate area with significantly fewer neurons in the ventral horn, supporting a recent survey of $\mathrm{GFP}^{+}$INs in these mice by Dougherty et al. (2009). The average number of neuronal profiles in the lumbar segments was estimated from counts in at least eight transverse sections (100 $\mu \mathrm{m}$ thick) per spinal cord. The number of ventral $\mathrm{GFP}^{+}$INs was developmentally regulated, in agreement with previous findings that the number of ventral GABAergic neurons substantially decreases before birth (Ma et al., 1992; Allain et al., 2004). At E14, many ventral GFP ${ }^{+}$INs were clustered in the medial area ventral to the central canal in a region that resembles the future location of LVIII (Fig. 1). Their axons took a medioventral trajectory and crossed the ventral commissure to enter the contralateral side of the spinal cord. The average \pm SE number of somata per $100-\mu \mathrm{m}$-thick sections was $38 \pm 4$ ( $n=3$ spinal cords). It has been shown that numerous ventral GAD67 INs send commissural axons at similar embryonic ages, but their number decreases substantially after birth (Phelps et al., 1999). Similarly, the number of GFP ${ }^{+}$IN profiles greatly decreased in the spinal cords of GAD67::GFP mice after birth (Fig. 1). The average number of $\mathrm{GFP}^{+}$IN profiles in medial regions of LVIII in L2-L3 was $9 \pm 1.2$ at P2 $(n=3)$ and $7 \pm$ $0.9(n=3)$ in juvenile mice (P10-P11).
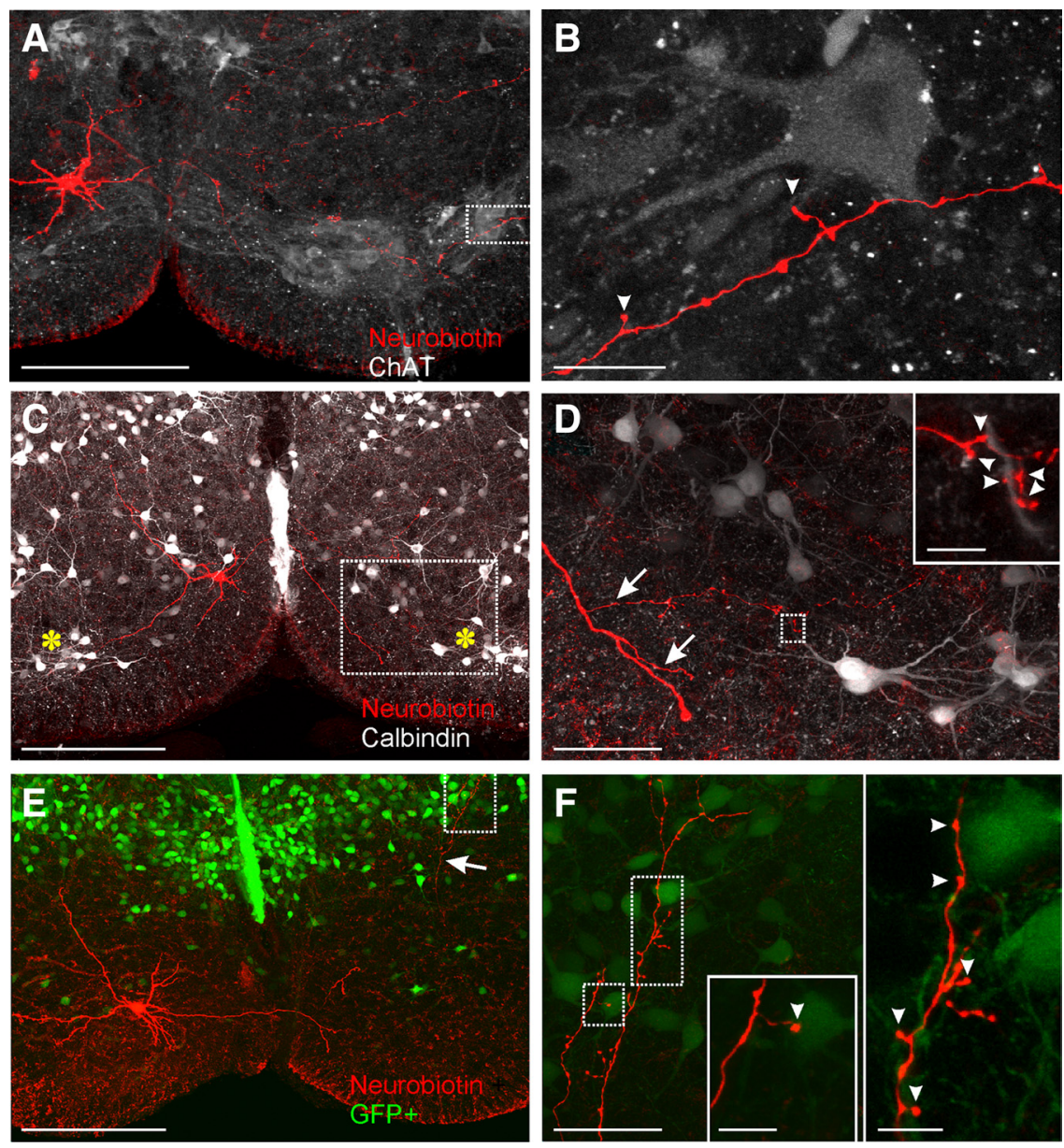

Figure 4. Synaptic contacts between commissural GFP ${ }^{+}$INs and contralateral neurons. A, A medium-magnification confocal image showing a Neurobiotin-filled (red, streptavidin 555) GFP ${ }^{+}$IN and ChAT-IR neurons (white, Cy5). Motor pools are located ventrally, whereas cholinergic interneurons are located dorsally around the central canal. One axonal branch passes through the medial and lateral motor pools. The dashed box region is shown at higher magnification in $\boldsymbol{B}$. $\boldsymbol{B}$, High-magnification confocal image of a Neurobiotin-filled axon collateral (streptavidin 555, red) establishing contacts (arrowheads) on ChAT-IR dendrites (Cy5, white) in the lateral motoneuron pool. C, A medium-magnification confocal image of a Neurobiotin-filled (red, streptavidin 555) $\mathrm{GFP}^{+}$neuron and calbindin-IR neurons (white, Cy5). The location of ventral calbindin-IR Renshaw cells are marked with yellow asterisks. Note the axonal branch projecting toward the Renshaw cell pool. The boxed area is shown at higher magnification in $\boldsymbol{D}$. $\boldsymbol{D}$, At higher magnification, several collateral branches (arrows) emerged from the parent axon and projected toward Renshaw cell pools. The more dorsal branch can be followed all the way toward a Renshaw cell dendrite (boxed area shown at higher magnification in the inset), leaving some en passant boutons along its route. Inset, Several varicosities (arrowheads) from the Neurobiotin-filled axon made contact along the dendritic process of a calbindin-positive cell within the Renshaw cell pool. $\boldsymbol{E}, \mathrm{A}$ medium-magnification image of a Neurobiotin-filled (red, streptavidin 555) GFP ${ }^{+}$IN as well as other GFP neurons. One axonal branch projected dorsally through contralateral GFP neurons (arrow). The region boxed is shown at higher magnification in $\boldsymbol{F}$. $\boldsymbol{F}$, were located in close apposition to other GFP ${ }^{+}$neurons throughout this region. Insets, Expanded views of the dashed box regions. Putative synaptic contacts (arrowheads) were made along both somas and dendrites of contralateral GFP-positive neurons. Scale bars: $A, C, E, 200 \mu \mathrm{m} ; \boldsymbol{B}, 20 \mu \mathrm{m} ; \boldsymbol{D}, \boldsymbol{F}, 50 \mu \mathrm{m}$; insets in $\boldsymbol{D}, \boldsymbol{F}, 10 \mu \mathrm{m}$.

Ventral neurons in the spinal cord of GAD67::GFP transgenic mice are distributed mostly in laminae VII and VIII, but our study focused on the large $\mathrm{GFP}^{+}$neurons in LVIII for two reasons. First, the majority of CINs in the mammalian spinal cord with target neurons in the contralateral ventral horn are found in LVIII (Harrison et al., 1986; Puskar and Antal, 1997; Stokke et al., 2002; Bannatyne et al., 2003; Matsuyama et al., 2006). Second, the $\mathrm{LVIII} \mathrm{GFP}^{+}$INs that are distributed within $250 \mu \mathrm{m}$ of the midline can be visually identified and targeted for electrophysiological and morphological analyses in longitudinally sectioned hemicords.

To confirm the GABAergic nature of $\mathrm{GFP}^{+}$INs, transverse slices were immunostained against GABA following the protocol 
A
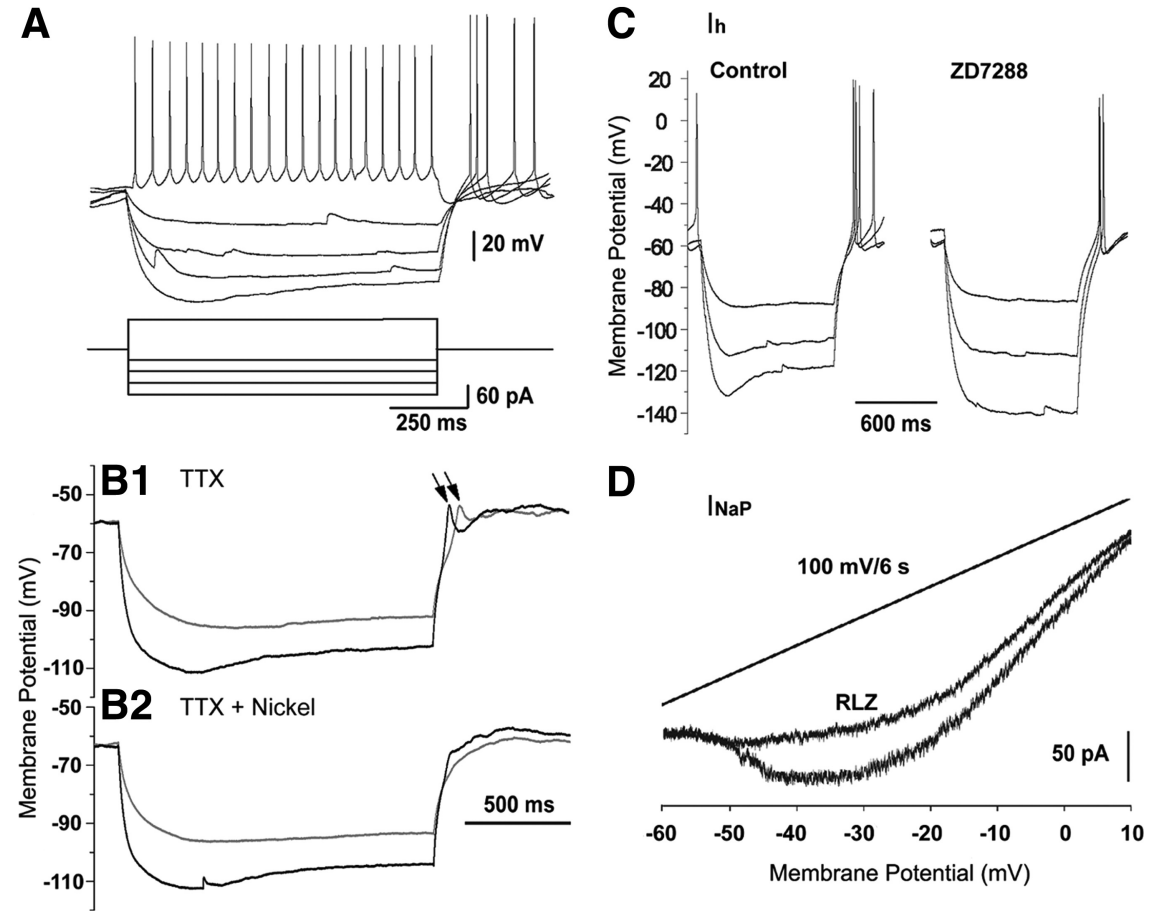

Figure 5. Electrophysiological properties of neonatal GFP ${ }^{+}$INs. $A$, Responses of a GFP ${ }^{+}$IN to prolonged positive and negative currents. Positive current injection ( $80 \mathrm{pA} / 1 \mathrm{~s})$ evoked repetitive firing $(19 \mathrm{~Hz})$ without spike-frequency adaptation. Negative current injections produced hyperpolarization-activated depolarization sags. Rebound action potentials were evident. Resting membrane potential was approximately $-55 \mathrm{mV}$. The input resistance was $604 \mathrm{M} \Omega . \boldsymbol{B}$, In a different cell, in the presence of TTX $(1 \mu \mathrm{m})$, subthreshold PIRs were generated at the break from hyperpolarizing currents (arrows). These were blocked by nickel (100 $\mu \mathrm{m}$ ) and partially recovered $30 \mathrm{~min}$ after nickel removal from the recording solution (data not shown). The input resistance was 702 $M \Omega$. C, Hyperpolarization-activated depolarization sags were produced in response to long hyperpolarization steps $(1 \mathrm{~s})$ at potentials more negative than $-90 \mathrm{mV}$. ZD7288 $(50 \mu \mathrm{m})$ blocked the depolarizations sags. $D, I_{\mathrm{NaP}}$ inward current was generated in response to a slow depolarization ramp ( $100 \mathrm{mV} / 6 \mathrm{~s})$ after blocking potassium and calcium currents. The region of negative slope conductance was significantly reduced by riluzole (RLZ; $10 \mu \mathrm{M})$.

described by Heinke et al. (2004). The number of GABA-IR cell bodies in the ventral horn varied considerably. In different preparations, $60-80 \%$ of $\mathrm{GFP}^{+}$INs in LVIII were GABA-IR (Fig. $2 A)$. Differences were attributable to variable penetration of the antibody throughout the sections, and, because of this rather poor penetration, it was uncertain whether $\mathrm{GFP}^{+}$INs that were not labeled with anti-GABA antibody were actually not GABAergic INs. We can conclude, however, that the majority of GFP ${ }^{+}$ INs displayed GABA immunoreactivity, although they were clearly only a small fraction of all the GABAergic INs detected in LVIII. It is known that, in these mice, only subpopulations of GABAergic cells are $\mathrm{GFP}^{+}$(Oliva et al., 2000). In the spinal cord of mature GAD67::GFP mouse, $86 \%$ of $\mathrm{GFP}^{+}$interneurons in lamina II are GABA-IR, but only one-third of the GABAergic interneurons express GFP (Heinke et al., 2004). In fact, the restricted labeling is a great advantage because it allows targeting a rather discrete group of GABAergic neurons.

\section{Large LVIII GFP ${ }^{+}$interneurons extend axons contralaterally} and arborize in multiple laminae

$\mathrm{GFP}^{+}$neurons were filled intracellularly with Neurobiotin (0.5$0.7 \%)$ during whole-cell recording $(n=19)$, and 15 of those were examined further to characterize their axonal projections and arborizations. Four cells were discarded because of either poor labeling $(n=1)$ or very different morphological features and location $(n=3)$. Our morphological and electrophysiological experiments focused primarily on the large LVIII GFP ${ }^{+}$INs (soma diameter, 25-40 $\mu \mathrm{m}$ ) distributed up to $\sim 250 \mu \mathrm{m}$ lateral to the midline. Morphological characterizations were performed in 300- $\mu$ m-thick transverse sections counterstained with fluorescent Nissl to establish laminar boundaries. All 15 neurons examined had relatively homogenous morphological properties characterized by relatively large cell bodies and multipolar dendritic arborizations that extended throughout ipsilateral LVIII and LVII and sometimes into dorsal horn laminae and showed at least the initial trajectory of their axon (Fig. $3 A, B$ ). In nearly half of the preparations ( 7 of 15 , 47\%) Neurobiotin labeling spread to nearby ipsilateral somata that were GFP negative. Some of the neurons were $\sim 100 \mu \mathrm{m}$ away from the soma of the filled neuron (Fig. $3 A$, arrowheads). These findings raised the possibility of dendrodendritic gap junctions between GFP-positive and GFP-negative neurons. Evidence for electrical coupling came also from experiments in which fast inward currents persisted after blocking glutamatergic transmission with the nonNMDA and NMDA receptor antagonists, CNQX $(20 \mu \mathrm{M})$ and D-APV $(20 \mu \mathrm{M})$ (see Fig. $8 B$ ).

Sixty percent of the neurons analyzed (9 of 15) displayed Neurobiotin-filled axons that crossed the midline through the ventral white commissure (vwm) just ventral to the central canal, and, in one additional neuron, the axon displayed a similar initial trajectory toward the vwm but was lost at the cut surface of the section before crossing. In another case, the axon was lost at the surface of the section very close to its origins from the cell body, and its initial trajectory could not be discerned. Finally, one $\mathrm{GFP}^{+}$neuron had an ipsilaterally projecting axon and arbor, and, in three other neurons, we could not identify labeled axons. Of the nine cells with axons crossing the midline, eight had relatively well-labeled uncut axonal branches that projected contralaterally into various dorsal and ventral laminae (Fig. 3C). None of these axons left axon collaterals in the ipsilateral side in which the cell bodies were located. All eight neurons (100\%) displayed axonal branches and terminal arbors in contralateral LVIII. Beyond LVIII, there was some variability of the location of additional axonal branches, but these were probably related to the quality of axon labeling rather than actual variability in axonal projections within this group of neurons. Four cells (50\%) had welllabeled axons that projected as far as medial LIX, and two (25\%) had complete labeled contralateral axonal arborizations that projected all the way to lateral LIX motoneuron pools. Axon branches and terminal arborizations were found in medial LVII (4 of 8 cells, 50\%), dorsal LVII ( 3 of $8,38 \%$ ), ventral LVII ( 3 of $8,38 \%$ ), and dorsal horn LIV and LV (3 of 8, 38\%). Figure 3 shows an example of a LVIII Neurobiotin-labeled $\mathrm{GFP}^{+}$IN with a well-labeled contralateral axonal arbor through all these laminae (Fig. 3C). In this example, axonal branches entered the lateral funiculus at various dorsoventral points after coursing through the gray matter.

Presumed synaptic varicosities and boutons were found throughout all of these laminar regions (Fig. $3 E-G$ ). In well- 
labeled axons, the relative proportion of terminal varicosities was always much greater in LVIII than in other laminae. In Nissl counterstained images, Neurobiotin-filled axonal varicosities appeared like en passant or terminal boutons that contacted many neurons in all laminae. Some Neurobiotinlabeled $\mathrm{GFP}^{+}$INs were processed with post hoc immunohistochemistry to analyze possible synaptic interactions with other $\mathrm{GFP}^{+}$ INs, Renshaw cells, and motoneurons. Renshaw cells were identified by their CB immunoreactivity, and motoneurons were detected by their expression of ChAT. Some axonal branches passed through the contralateral medial and lateral ChAT-IR motoneuron pools in the ventral horn (Fig. $4 A$ ), as well as the contralateral CB-IR Renshaw cell pool (Fig. 4C) and into contralateral regions containing high densities of $\mathrm{GFP}^{+}$neurons (Fig. 4E). All of these axons formed varicosities that were juxtaposed along somas and dendrites of motoneurons (Fig. 4B), Renshaw cells (Fig. 4D), and $\mathrm{GFP}^{+}$INs (Fig. 4F). Together, these observations suggest that axons of LVIII GFP ${ }^{+}$ INs crossed the midline and projected into contralateral LVIII from where they diverged into different areas of the contralateral spinal cord and appeared to establish synaptic contacts with multiple neuronal groups, including motoneurons. Based on their axonal projections, it is reasonable to suggest that these interneurons influence the activity of many different neuronal populations in the contralateral side of the cord.

\section{Intrinsic properties of $\mathrm{GFP}^{+}$INs}

Electrophysiological properties were examined in LVIII GFP ${ }^{+}$neurons $(n=19)$ that were filled with Neurobiotin for morphological analyses. Our preliminary observations suggested that most large LVIII $\mathrm{GFP}^{+}$neurons produced hyperpolarization-activated depolarization sags. Therefore, to increase the probability of recording from the same group of $\mathrm{GFP}^{+}$INs, only neurons that generated the depolarization sags were included in the analysis. The depolarization sags were generated at potentials more negative than $-90 \mathrm{mV}$ (Fig. $5 A-C)$. Characteristically, LVIII GFP ${ }^{+}$INs fired spontaneously at a relatively constant frequency $(\geq 3 \mathrm{~Hz})$ at resting membrane potentials of -50 to $-60 \mathrm{mV}$. The average \pm SE input resistance was $649.2 \pm 60.8 \mathrm{M} \Omega(n=19)$, varying from 400 to $850 \mathrm{M} \Omega$. The average membrane capacitance was $36.5 \pm 3.3 \mathrm{pF}$. The rheobase ranged from $40-60 \mathrm{pA}$, and prolonged depolarization steps generated repetitive firing without significant frequency adaptation at frequencies $<50 \mathrm{~Hz}$. The average amplitude of the AHP was $17.9 \pm 1.9 \mathrm{mV}$, ranging from 15 to $25 \mathrm{mV}$ (Fig. $5 A$ ). The large AHP might have contributed to the characteristic tonic firing of LVIII GFP $^{+}$INs. In all GFP ${ }^{+}$INs, a break from prolonged hyperpolarizing current pulses resulted in postinhibitory rebound (PIR) that generated action potentials (Fig. 5A, C).

We next examined whether voltage-activated currents often found in rhythmically active spinal neurons were part of the ionic repertoire of $\mathrm{GFP}^{+}$INs. These included the T-type calcium current $\left(I_{\mathrm{T}}\right)$, hyperpolarizing-activated inward current $\left(I_{\mathrm{h}}\right)$, and persistent sodium current $\left(I_{\mathrm{NaP}}\right)$. For this purpose, we analyzed a sample of large LVIII GFP ${ }^{+}$neurons expressing the characteristic electrophysiological responses to depolarizing and hyperpolarizing current pulses described above. Most of these cells were studied in the hemisected spinal cord. We first examined whether the PIRs were generate by $I_{\mathrm{T}}$, a calcium current found in rhythmogenic neurons such as Hb9 interneurons (Wilson et al., 2005), a cluster of neurons in the locomotor circuitry of the mouse spinal cord (Hinckley et al., 2005b) (for review, see Brownstone and Wilson, 2008; Ziskind-Conhaim et al., 2010), and in neurons in the lamprey locomotor network (Tegnér et al., 1997). The role of $I_{\mathrm{T}}$ in mediating PIRs was explored in the presence of tetrodotoxin (TTX) $(1 \mu \mathrm{M})$ to block the rebound action potentials. TTXresistant, subthreshold PIRs were generated at the break from hyperpolarization steps (Fig. 5B1) $(n=6)$, and their amplitude increased as a function of membrane hyperpolarization. The PIRs were inhibited by nickel $(100 \mu \mathrm{M})$, a blocker of $I_{\mathrm{T}}$ (Fig. 5B2) ( $n=4$ of 4 ), suggesting that $I_{\mathrm{T}}$ contributed to the rebound potentials. 


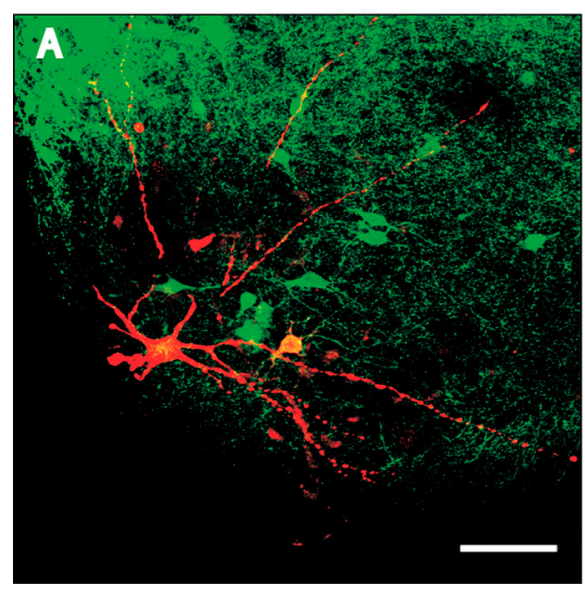

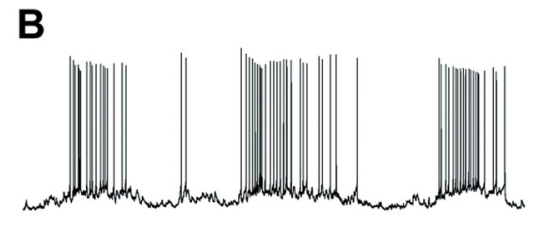

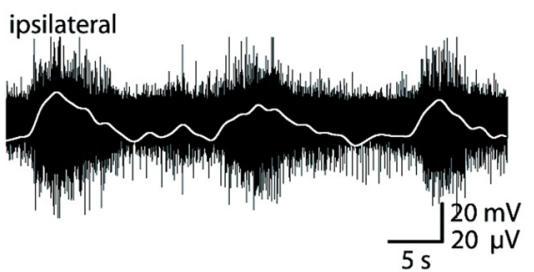

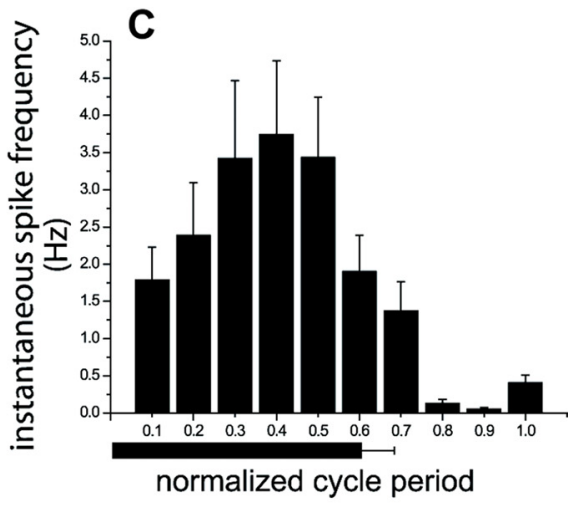

normalized cycle period

Figure 7. Membrane oscillations and rhythmic firing of a LVIII GFP ${ }^{+}$IN were in-phase with ipsilateral bursts of motor outputs. $A$, Confocal image of the Neurobiotin-filled interneuron reconstructed from 76 optical sections $\left(0.5 \mu \mathrm{m}\right.$ Z-steps, $37.5 \mu \mathrm{m}$ travel in $Z$-axis). Scale bar, $100 \mu \mathrm{m}$. B. The firing rate in this GFP ${ }^{+}$IN (top trace) increased twofold to threefold during ipsilateral motor output bursts (bottom trace). Electroneurograms were rectified and smoothed (white trace). $\boldsymbol{C}$, Histogram of instantaneous action potential frequency as a function of normalized cycle period demonstrated a significantly higher firing rate during ipsilateral motor bursting ( $n=10$ cycles, $p<0.05)$. Errors bars indicate SE.

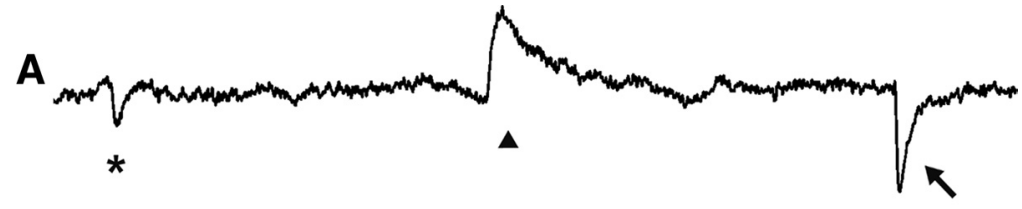

B1 Control

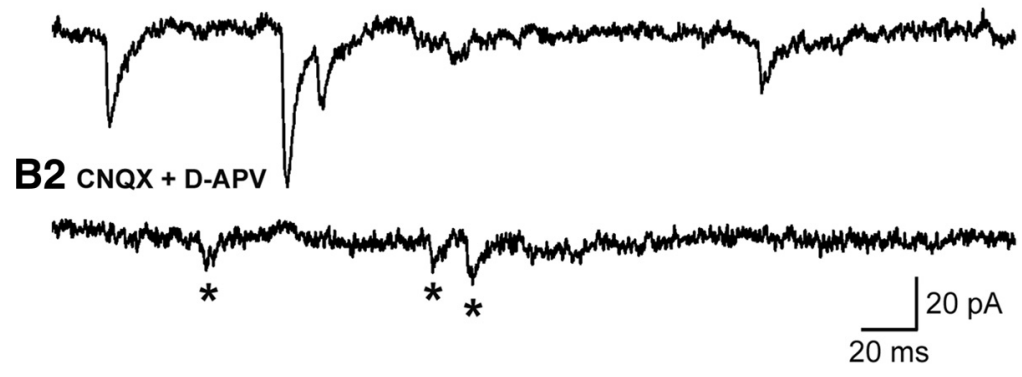

C

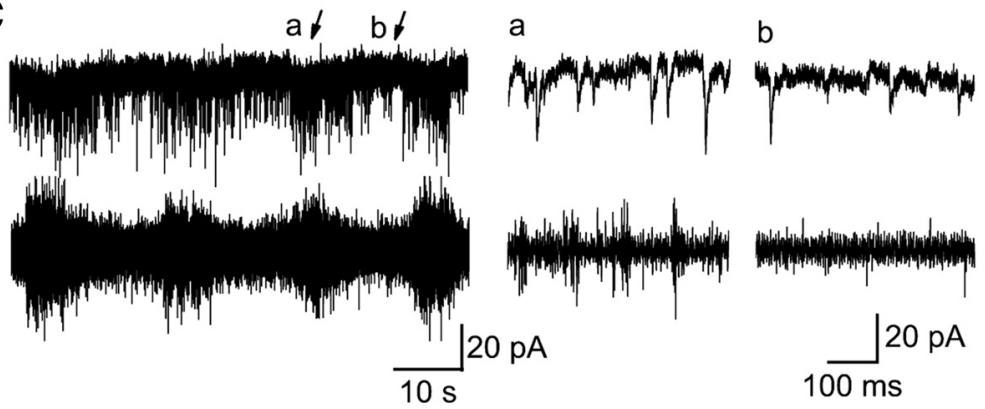

Figure 8. The frequency of EPSCS increased significantly during episodes of motor bursts. $\boldsymbol{A}$, Three types of synaptic potentials were evident in all GFP ${ }^{+}$INs at holding potentials more positive than $-50 \mathrm{mV}$ : fast-decaying inward EPSCS (arrow), slow-decaying outward IPSCS (arrowhead), and inward currents generated by action potentials in prejunctional neurons electrically coupled to the GFP ${ }^{+}$IN recorded from (asterisk). Holding potential, $-40 \mathrm{mV} . B 1$, In a different GFP ${ }^{+} \mathbb{N}$, only inward currents were recorded at a holding potential of $-60 \mathrm{mV}$. B2, CNQX (20 $\mu \mathrm{m})$ and D-APV (20 $\mu \mathrm{m})$ blocked the EPSCs but not the currents generated by action potentials in electrically coupled neuron(s) (asterisks). C, The frequency of EPSCs in GFP ${ }^{+}$INs (top trace) increased during ipsilateral motor output bursts (bottom trace). Traces of voltage-clamp recording and electroneurograms were expanded to demonstrate the higher EPSC frequency during the motor burst (a) compared with the interburst phase $(\boldsymbol{b})$.

One of the voltage-dependent currents that is expressed in many locomotor-related spinal neurons is the $I_{\mathrm{h}}$. This current has been shown in descending CINs (Butt et al., 2002) as well as rhythmically active V2a glutamatergic interneurons (Zhong et al., 2010) and lo- comotor-related neurons in c-Fos-eGFP mice (Dai and Jordan, 2010). To investigate whether $I_{\mathrm{h}}$ produced the characteristic depolarizing sags observed in all LVIII GFP ${ }^{+}$ cells in response to hyperpolarizing pulses, experiments were performed in the presence of ZD7288 (4-ethylphenylamino-1,2dimethyl-6-methylaminopyrimidinium chloride), a selective blocker of $I_{\mathrm{h}}$. Exposure to ZD7288 (50 $\mu \mathrm{M})$ suppressed these potentials (Fig. $5 C)(n=4)$, confirming the role of $I_{\mathrm{h}}$ in their generation.

$I_{\mathrm{NaP}}$ has been characterized in various rhythmogenic neuronal populations, including Hb9 INs in which $I_{\mathrm{NaP}}$ plays a key role in generating subthreshold membrane oscillations in synaptically isolated preparations (Tazerart et al., 2008; ZiskindConhaim et al., 2008). It was also described in locomotor-related commissural inhibitory interneurons (Zhong et al., 2007). $I_{\mathrm{NaP}}$ was generated in $\mathrm{GFP}^{+}$INs by a slow depolarization ramp with a rate adjusted to avoid action potential generation (Fig. 5D). The sodium current was isolated by blocking the majority of potassium and calcium currents. To block potassium currents, cesium was included in the pipette, and tetraethylammonium $(20 \mu \mathrm{M})$ and $4-\mathrm{AP}(4 \mu \mathrm{M})$ were added to the extracellular solution. Calcium currents were blocked by cadmium (300 $\mu \mathrm{M})$ (Ziskind-Conhaim et al., 2008). All five neurons tested showed the characteristic region of negative slope in the $I-V$ plot that resulted from activation of $I_{\mathrm{NaP}}$ during the slow depolarization ramp (Fig. 5D). The threshold for generating the inward current was $-55.7 \pm 2.0 \mathrm{mV}$ (mean $\pm \mathrm{SE} ; n=5)$, and it had an average peak amplitude of $43.2 \pm 6.7 \mathrm{pA}$. The negative slope conductance was greatly reduced by riluzole $(10 \mu \mathrm{M})$, a blocker of $I_{\mathrm{NaP}}$ (Fig. $\left.5 D\right)(n=5)$, validating its classification as $I_{\mathrm{NaP}}$. 
Correlation between locomotor-like rhythmic firing in LVIII $\mathrm{GFP}^{+}$INs and segmental motoneurons

Excitatory and inhibitory commissural interneurons are part of a complex rhythm-coordinating circuitry that regulates alternating activities of neurons on both sides of the spinal cord in all vertebrates (Soffe et al., 1984; Jankowska, 2001; Grillner, 2006; Kiehn, 2006). Therefore, we examined whether the firing patterns in $\mathrm{GFP}^{+}$INs were correlated with locomotor-like activity in contralateral and ipsilateral motoneurons. Locomotor-like activity was induced neurochemically with a rhythmogenic mixture that included NMA (5 $\mu \mathrm{M})$, serotonin $(10 \mu \mathrm{M})$, and dopamine (50 $\mu \mathrm{m}$ ), as described in our recent reports (Hinckley et al., 2010; Ziskind-Conhaim et al., 2010). Rhythmic activities were confirmed as locomotor-like rhythms if they alternated between leftright L2 or L3 ventral roots or between ipsilateral L2 and L5 ventral roots. To visually target $\mathrm{GFP}^{+}$INs for whole-cell recordings, spinal cords were transected longitudinally with the intention of sectioning up to $250 \mu \mathrm{m}$ lateral to the midline. Such sections produced two asymmetrical hemicords: one with GFP ${ }^{+}$ INs with contralateral ventral roots attached and the second, a smaller hemicord, with intact ipsilateral ventral roots. GFP ${ }^{+}$INs exposed near the cut surfaces that had similar voltage responses to negative and positive current injections shown above (Fig. $5 \mathrm{~A}$ ) were tested for their rhythmogenic activity. In approximately half the experiments, interneurons were filled with Neurobiotin to confirm their location, morphological characteristics, and axonal projections. Axonal projections did not extend to distances longer than $250 \mu \mathrm{m}$ from the cell body along the rostrocaudal axis, suggesting that $\mathrm{GFP}^{+}$INs synapse onto target neurons distributed in the same or closely adjacent segments.

To test our hypothesis that LVIII GFP ${ }^{+}$INs were part of the locomotor rhythm-coordinating networks, the patterns of their induced rhythmic firing were correlated with electroneurograms of segmental ventral roots $(n=35)$. The cycle period varied considerably, ranging from an average \pm SE of $12.2 \pm 5.3 \mathrm{~s}(n=$ $5)$ in the large hemicord with attached contralateral ventral roots to $18.7 \pm 4.7 \mathrm{~s}(n=17)$ in the smaller hemicord. We have reported previously that the midsagittal cut increased the cycle period from $5.0 \mathrm{~s}$ in the intact cord to $8.9 \mathrm{~s}$ in the hemicord (Hinckley et al., 2005b), and similar, slower rhythms have been reported in the lamprey hemisected spinal cord (Cangiano and Grillner, 2003). The slower bursts in the smaller hemisected cord might have resulted from an elimination of neuronal components that dictate faster rhythms in the spinal cord. It is unlikely that weaker synaptic drive was responsible for the lower frequency rhythms in the smaller hemicords, because the synaptic activity in these hemicords was as robust as the activity in the larger hemicords (see Figs. 8, 9).

Whole-cell recordings were performed only after the generation of stable, rhythmic ventral root electroneurograms. Voltage membrane oscillations and rhythmic firing were recorded in 63\% of the neurons examined ( $n=22$ of 35$)$. The rest of the neurons exhibited a nonrhythmic firing pattern that was not correlated with bursts of segmental ventral roots $(n=13)$. In the majority of $\mathrm{GFP}^{+}$INs examined in large hemicords $(n=5$ of 8$)$, the induced locomotor-like rhythmic firing was out-of-phase with bouts of motor activity in the contralateral ventral roots (Fig. 6).

In the smaller hemicords, a similar proportion of $\mathrm{GFP}^{+}$INs ( $n=17$ of 27 ) displayed membrane voltage oscillations in phase with episodes of motor bursts recorded in the segmental, ipsilateral ventral roots (Fig. 7). Based on these observations and the finding that LVIII $\mathrm{GFP}^{+}$INs did not project to the ipsilateral motor column, we concluded the following: (1) LVIII GFP ${ }^{+}$
A

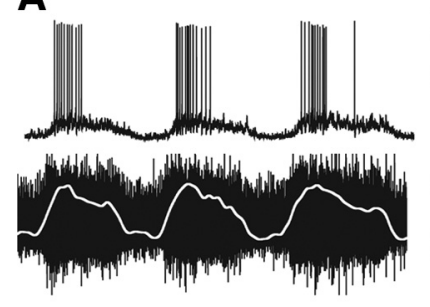

B

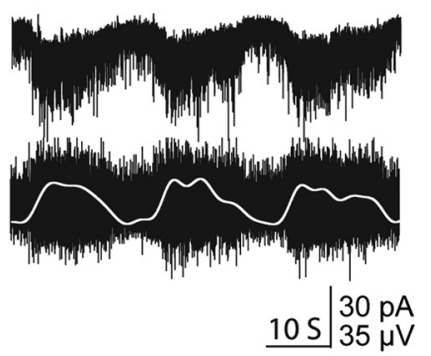

C

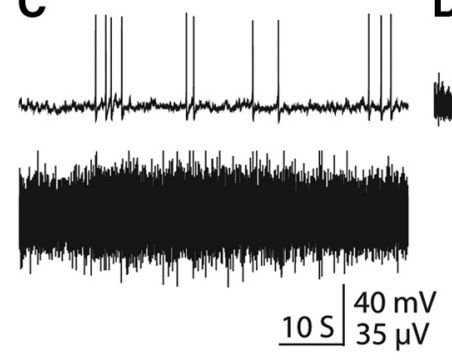

D

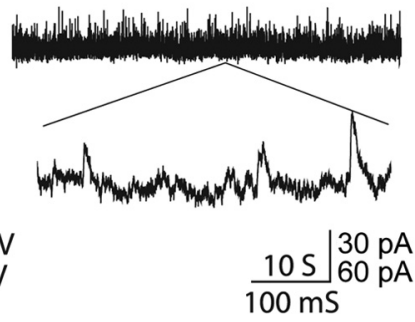

Figure 9. Membrane voltage oscillations were dependent on glutamatergic synaptic transmission. Whole-cell current-clamp $(\boldsymbol{A}, \boldsymbol{C})$ and voltage-clamp $(\boldsymbol{B}, \boldsymbol{D})$ recordings in a GFP ${ }^{+}$IN. $\boldsymbol{A}$, Neurochemically induced subthreshold voltage oscillations and rhythmic firing (top trace) were in-phase with ventral root potentials (bottom trace) recorded in the ipsilateral side of the spinal cord. $\boldsymbol{B}$, Using voltage-clamp mode, episodes of current oscillations and bursts of EPSCs (top trace) were recorded in the same GFP ${ }^{+}$IN shown in $\boldsymbol{A}$. C, Ten minute exposure to CNQX (20 $\left.\mu \mathrm{M}\right)$ completely abolished the induced voltage oscillations and episodes of motor bursts. Same scale bar for traces shown in $\boldsymbol{A}$ and $\boldsymbol{C}$. $\boldsymbol{D}$, At a holding potential of $-40 \mathrm{mV}$, mostly large outward currents (IPSCs) were recorded in voltage-clamp mode and in the presence of CNQX (top trace). These were apparent at an expanded time scale (bottom trace) (scale bar, $100 \mathrm{~ms}$ ). Calibration: 30 and $60 \mathrm{pA}$ for top and bottom traces, respectively.

commissural INs receive rhythmic excitatory drive that is inphase with inputs to ipsilateral motoneurons, and (2) rhythmic firing in LVIII GFP ${ }^{+}$INs does not suppress locomotor activity in ipsilateral motoneurons. These findings combined with our morphological data suggest that LVIII GFP ${ }^{+}$INs provide rhythmic GABAergic inhibition to contralateral motoneurons and interneurons that is in-phase with ipsilateral motor activity.

\section{The contribution of synaptic inputs to rhythm generation}

Synaptic inputs play a central role in rhythm initiation by changing membrane potentials and activating distinct voltageactivated conductances that trigger rhythmic firing and, not less importantly, terminate burst activity in locomotor-related neurons (for review, see Grillner et al., 1998; Harris-Warrick, 2002). To determine whether excitatory and inhibitory synaptic inputs contributed to the onset and termination of rhythmic membrane depolarizations in $\mathrm{GFP}^{+}$INs, voltage-clamp recordings were performed to estimate the frequency of spontaneous EPSCs and IPSCs during the burst and interburst phases. IPSCs had reversal potentials more negative than $-50 \mathrm{mV}$; therefore, to separate the inward IPSCs from EPSCs, recordings were performed at a holding potential more positive than $-50 \mathrm{mV}$ (Seebach and ZiskindConhaim, 1994; Gao et al., 1998). At a membrane potential of $-40 \mathrm{mV}$, IPSCs were recorded as outward currents and EPSCs as inward currents. Inwardly directed fast currents generated by action potentials in electrically coupled neurons were also detected (Fig. $8 \mathrm{~A}$ ). The amplitude of these currents did not change as the function of membrane potential (data not shown) (but see Hinckley and Ziskind-Conhaim, 2006), and they were not blocked by exposure to CNQX $(20 \mu \mathrm{M})$ and D-APV $(20 \mu \mathrm{M})$ (Fig. 
A1
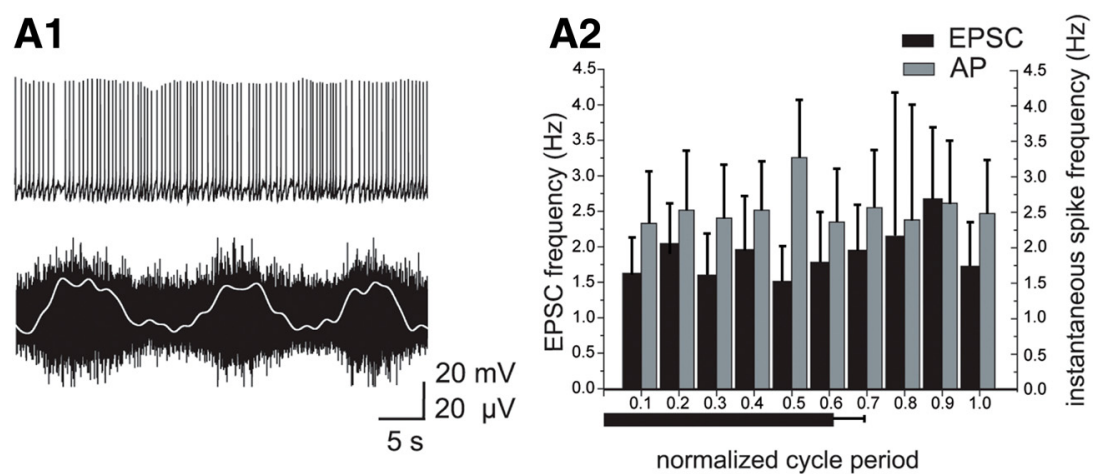

B1

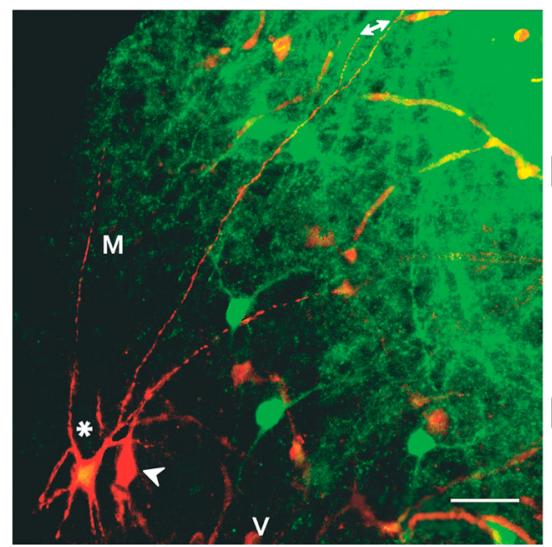

B2 Spontaneous

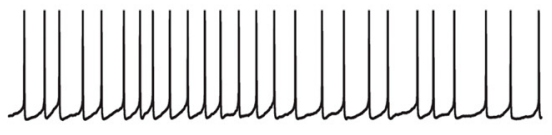

B3 + cocktail

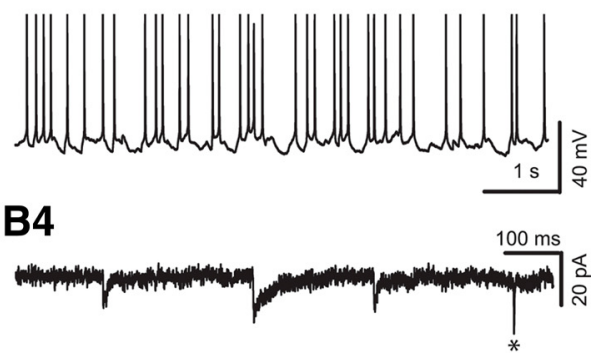

Figure 10. Locomotor-like rhythms could not be triggered in a fraction of LVIII GFP ${ }^{+}$INs with relatively low-frequency EPSCS. A1, Exposure to the rhythmogenic mixture triggered bursts of motor activity but did not convert the tonic firing into episodes of rhythmic firing. A2, Histogram of EPSC frequency and instantaneous spike frequency as a function of normalized cycle period. Neither EPSC nor spike frequencies were correlated with rhythmic motor activity (solid bar). B1, Morphology of a Neurobiotin-filled LVIII GFP $^{+}$IN (asterisk) labeled during whole-cell recording (B2-B4). This cell had a similar size and large dendritic arborization as neurons that produced locomotor-like rhythms. One of the dendrites (marked by the double arrow) extended into LVI. Neurobiotin spread to an adjacent GFP-negative neuron (arrowhead), suggesting gap junction coupling between them. M, Medial; $V$, ventral. Scale bar, $50 \mu \mathrm{m}$. The image was constructed from superimposing 28 confocal optical sections (1 $\mu \mathrm{m} Z$-steps). B2, Spontaneous tonic firing characteristic of LVIII GFP ${ }^{+}$INs. B3, Exposure to the rhythmogenic mixture triggered episodes of brief membrane depolarizations and irregular firing. Membrane potential in $B 2$ and $\boldsymbol{B} 3$ varied from -53 to $-57 \mathrm{mV}$. Action potentials are truncated. B4, Example of the highest-frequency inward currents recorded in this neuron in the presence of the rhythmogenic mixture. Three EPSCS were recorded during the $1 \mathrm{~s}$ period shown. The short-duration inward current (asterisk) was likely generated by action potential in prejunctional electrically coupled neuron. Holding potential was $-60 \mathrm{mV}$.

$8 B)(n=3)$. These were suppressed by carbenoxolone $(100 \mu \mathrm{M}$, $n=3$ ), a gap junction blocker (Hinckley and Ziskind-Conhaim, 2006). Based on these findings, we concluded that the currents were generated by action potentials in prejunctional neurons.

Similar to all CINs, firing episodes in LVIII GFP ${ }^{+}$INs were triggered by rhythmic excitatory drive. During induced locomotor-like rhythms, the frequency of EPSCs significantly increased from an average $\pm \mathrm{SE}$ of $5.2 \pm 0.8 \mathrm{~Hz}(n=5)$ during the interburst phase to $11.5 \pm 1.3 \mathrm{~Hz}$ at the peak of motor bursting $(p<0.05)$ (Figs. $8 C, 9 B)$. In contrast, the average frequency of IPSCs did not change during the cycle period, ranging from $2.8 \pm$ $0.4 \mathrm{~Hz}$ during the burst to $3.1 \pm 0.2 \mathrm{~Hz}$ in the interburst phase. This implied that the termination of membrane oscillations and rhythmic firing was not controlled by inhibitory inputs as was the case in unidentified interneurons and CINs in the neonatal rat spinal cord (Raastad et al., 1997; Butt et al., 2002). It is conceivable that the reduction in excitatory drive to $\mathrm{GFP}^{+}$INs contributed to the termination of oscillatory membrane depolarizations. The pattern of rhythmic activity is determined by the dynamic interplay between synaptic transmission and voltage-activated ionic currents, and those currents might regulate the duration of membrane oscillations and rhythmic firing in $\mathrm{GFP}^{+}$INs. $I_{\mathrm{NaP}}$ contributes to the onset of locomotor-like rhythms in synaptically isolated $\mathrm{Hb} 9$ INs (Tazerart et al., 2008; Ziskind-Conhaim et al., 2008), and we have proposed that its slow inactivation (Butera et al., 1999; Magistretti and Alonso, 1999) is responsible for terminating $I_{\mathrm{NaP}}$-triggered low-frequency membrane oscillations in the rhythmogenic Hb9 INs (Ziskind-Conhaim et al., 2010).

CNQX $(20 \mu \mathrm{M})$ suppressed EPSCs and rhythmic activity in both $\mathrm{GFP}^{+}$INs and motoneurons (Fig. 9C), suggesting that glutamatergic synaptic transmission played an important role in generating locomotorlike rhythms in both neuronal populations. The frequency of spontaneous IPSCs increased approximately twofold $(5.7 \pm 0.6$ $\mathrm{Hz} ; n=3$ ) after suppressing glutamatergic transmission (Fig. 9D). It is therefore possible that blocking glutamatergic excitatory transmission revealed IPSCs that were masked before by the frequent and largeamplitude EPSCs. An alternative explanation is that blocking glutamatergic neurotransmission resulted in disinhibition of inhibitory inputs onto LVIII GFP ${ }^{+}$INs. It should be noted that because blocking glutamatergic transmission suppressed the induced locomotor-like activity, it was impossible to examine the specific contributions of $I_{\mathrm{T}}, I_{\mathrm{h}}$, and $I_{\mathrm{NaP}}$ to rhythm generation in $\mathrm{GFP}^{+}$INs.

In approximately one-third of LVIII $\mathrm{GFP}^{+}$INs in the large and small hemicords $(n=13$ of 35$)$, exposure to the rhythmogenic mixture did not convert the relatively constant firing to rhythmic firing (Fig. 10A1). Low-frequency EPSCs were recorded in these neurons, ranging from 1.5 to $2.6 \mathrm{~Hz}$ (average, $1.8 \mathrm{~Hz}$ ), and their frequency did not increase during the bouts of motor activity (Fig. 10A2). Therefore, it is reasonable to assume that the failure to produce rhythmic activity resulted from low-frequency excitatory drive to these interneurons. The longitudinal sectioning used to obtain the hemicord might have damaged some of the networks that provide rhythmic excitatory inputs to $\mathrm{GFP}^{+} \mathrm{INs}$, resulting in low-frequency excitatory drive. The firing pattern in these neurons became less regular in the presence of the mixture with a tendency to oscillate in the form of frequent episodes of short membrane depolarizations that lasted $<1 \mathrm{~s}$ (Fig. 10 B3). It is possible that, in preparations with higher-frequency EPSCs (Figs. $8 C, 9 B)$, the increased excitatory drive during the burst phase was responsible for maintaining membrane depolarizations for durations longer than $5 \mathrm{~s}$. In this sense, the presence of some nonrhythmogenic LVIII GFP ${ }^{+}$INs could be the consequence of variable preservation of functional synaptic inputs in these reduced preparations. Alternatively, this group of $\mathrm{GFP}^{+}$INs could represent a different subpopulation of GABAergic INs that becomes rhythmically active at a different pattern/strength of synaptic inputs. A certain threshold of synaptic drive for recruitment 
Table 1. Similar electrical properties characterized rhythmically and nonrhythmically firing LVIII GFP ${ }^{+}$INs

\begin{tabular}{lcc}
\hline & Rhythmic firing & Nonrhythmic firing \\
\hline$R_{\text {in }}(\mathrm{M} \Omega)$ & $574.8 \pm 67.6$ & $758.8 \pm 87.4$ \\
$C_{\mathrm{m}}(\mathrm{pF})$ & $39.2 \pm 3.4$ & $30.7 \pm 3.8$ \\
Rheobase $(\mathrm{pA})$ & $53.6 \pm 6.4$ & $47.5 \pm 6.4$ \\
AP half-width (ms) & $2.7 \pm 0.1$ & $2.9 \pm 0.2$ \\
AHP amplitude (mV) & $17.4 \pm 1.0$ & $18.9 \pm 0.8$ \\
& $n=22$ & $n=13$ \\
\hline
\end{tabular}

Properties that were examined during exposure to the rhythmogenic mixture: input resistance $\left(R_{\text {in }}\right)$, membrane capacitance $\left(C_{m}\right)$, rheobase, action potential (AP) half-width, and AHP amplitude.

into rhythmogenic networks has been documented in zebrafish in which groups of excitatory INs are differentially recruited with the large INs being recruited at faster speeds (McLean et al., 2008). A similar principle might apply to the nonrhythmogenic $\mathrm{GFP}^{+}$that could be recruited at a different frequency than that induced in our study. Two observations imply that neurons that could not be recruited into rhythmic firing were not fundamentally different from the ones capable of producing rhythmic firing. First, Neurobiotin filling suggested that their size, anatomical features and complex dendritic structure were similar to those of rhythmically firing LVIII GFP ${ }^{+}$INs. Second, they shared similar electrophysiological properties (Table 1) and firing patterns generated in response to depolarizing currents. Thus, the more plausible hypothesis for their nonrhythmic activity is the requirement of synaptic inputs that were missing in our experimental conditions.

\section{Discussion}

In this study, we described a homogenous subpopulation of LVIII locomotor-related GABAergic CINs that can be readily visualized in the neonatal spinal cord of a particular strain of GAD67::GFP transgenic mice. To the best of our knowledge, this is the first characterization of LVIII commissural GABAergic CINs that are likely to modulate the activity of contralateral motoneurons and a number of contralateral premotor interneuronal circuits in the mammalian spinal cord. As such, these interneurons probably contribute to the coordination of left-right alternating locomotor rhythms.

\section{GFP ${ }^{+}$INs are characterized by large dendritic arborizations and extensive contralateral axonal targets} Neurobiotin-filled $\mathrm{GFP}^{+}$INs extended multipolar dendritic arbors for distances that often exceeded $500 \mu \mathrm{m}$ in the transverse plane. Such large dendritic arbors suggest that the neurons sample activity from a variety of inputs in many regions of the spinal cord. Previous studies have described a wide range of dendritic arbor sizes in intracellularly filled LVIII CINs in the spinal cord of adult cats (Bannatyne et al., 2003; Matsuyama et al., 2004) and neonatal mice (Quinlan and Kiehn, 2007), some having large dendritic fields similar to those reported here. Based on their distinctive pattern of axonal projections and similar electrophysiological properties, we propose that the large $\mathrm{GFP}^{+}$INs in LVIII constitute a relatively uniform population. In contrast, smaller $\mathrm{GFP}^{+}$neurons frequently located in neighboring LVII (data not shown) had diverse electrophysiological properties, smaller dendritic arbors, and axonal projections that could be ipsilateral and/or contralateral.

The axons crossed the ventral commissure and branched into contralateral laminae VII and VIII as do glutamatergic and glycinergic CINs (for review, see Jankowska, 2008; Kiehn et al., 2010). However, unlike other identified excitatory and inhibitory CINs, axons of LVIII GFP ${ }^{+}$INs also extended into dorsal laminae in the segmental contralateral side. A similar pattern of Golgi-stained axonal projections of CINs of unknown phenotype has been shown in the spinal cord of P4-P6 mice (Scheibel and Scheibel, 1966), but our findings demonstrate for the first time a widespread axonal projections of GABAergic CINs in contralateral medial and dorsal laminae. The projections displayed bouton-like varicosities that extended into medial and lateral motor columns and were in close apposition to lateral motoneurons and Renshaw cells. Putative synaptic contacts were also apparent on $\mathrm{GFP}^{+}$INs in laminae V-VI and on unidentified neurons, but they were more abundant in contralateral LVIII, possibly delivering GABAergic inputs to numerous contralateral CINs. If boutonlike varicosities are indeed active synaptic contacts, then these GABAergic CINs provide inhibitory drive to several neuronal populations probably with wide range of physiological functions. Paired patch-clamp recording will be required to demonstrate unambiguously the connectivity between LVIII GFP ${ }^{+}$INs and their potential contralateral target neurons. In two particularly well-filled axons, some collaterals entered the lateral funiculus at several dorsoventral locations as well as the ventral funiculus. It was difficult to ascertain in the slice preparation whether the axons ended there or they turned and continued in the rostral and/or caudal direction. However, Neurobiotin-filled long rostral/caudal projections were not evident in the hemisected cord. Finally, ipsilateral collaterals from these axons were not observed in any of the neurons, in contrast to previous descriptions based on Golgi impregnations of neonatal preparations (Scheibel and Scheibel, 1966).

To date, there has been only one report of a segmental CIN exerting GABAergic control of contralateral motoneurons in the neonatal mouse spinal cord (Quinlan and Kiehn, 2007). It is conceivable that, similar to the $\mathrm{GFP}^{+}$INs in our study, those neurons also target a significant proportion of the premotor network, which might explain the strong action of GABAergic synaptic transmission on the pattern of locomotor-like rhythms (Hinckley et al., 2005a). Suppressing GABA $_{\mathrm{A}}$ receptor- mediated synaptic transmission triggered robust motor bursts, synchronized the onset of left-right rhythmic motor outputs, and prolonged their duration. In comparison, blocking glycinergic synapses reduced the phase correlation without synchronizing the rhythms between the two sides of the cord.

Neurobiotin passage and the recording of carbenoxolonesensitive fast inward currents indicated the presence of gap junctions between GABAergic CINs and unknown neurons, indicating that the coupled network includes different types of neurons. It is likely that the properties of the gap junctions demonstrated in our study are different from those we previously characterized between excitatory Hb9 INs, because Neurobiotin spread between $\mathrm{Hb} 9$ INs was detected in $<7 \%$ of the preparations (Hinckley and Ziskind-Conhaim, 2006). Electrical coupling has a key role in synchronizing neuronal activity in the immature mammalian spinal cord (Tresch and Kiehn, 2000). Motoneurons are transiently electrically coupled in neonatal rats (Fulton et al., 1980; Walton and Navarrete, 1991; Chang et al., 1999), and it remains to be determined whether $\mathrm{GFP}^{+} \mathrm{IN}$ coupling is retained in juvenile mice that can walk, as is the case between Hb9 INs (Hinckley and Ziskind-Conhaim, 2006). Interestingly, electrical coupling that promotes fast synchronization of high-frequency potentials in GABAergic neurons has been well documented between relatively mature neurons in cerebellar networks (Mann-Metzer and Yarom, 1999), the neocor- 
tex (Galarreta and Hestrin, 1999; Gibson et al., 1999), and thalamus (Parker et al., 2009).

In summary, the widespread dendritic arbor, axonal projections, and electrical coupling all suggest that this subpopulation of GABAergic CINs integrates a large number of inputs and synchronize electrical activity in one side of the cord that is then transmitted to various neuronal targets in the contralateral side.

\section{GFP ${ }^{+}$INs are putative components of the locomotor circuitry}

Commissural interneurons in the mammalian spinal cord include heterogeneous groups of glutamatergic excitatory neurons and GABAergic and glycinergic inhibitory neurons. Lamina VIII is rich in CINs, and, based on electrophysiological recordings in the neonatal mouse spinal cord, excitatory CINs comprised $70 \%$ of ventral neurons with physiological actions on contralateral motoneurons, whereas $30 \%$ had inhibitory function (Butt and Kiehn, 2003; Quinlan and Kiehn, 2007). However, a reversed ratio of excitatory to inhibitory CINs was demonstrated morphologically using anatomical tracing and immunohistochemistry to identify all CINs regardless of their laminar position or the pattern of their projections to different laminae (Restrepo et al., 2009). In that study, glutamatergic excitatory neurons accounted for $40 \%$ of ventral CINs, whereas putative glycinergic and GABAergic CINs constitute 30 and $21 \%$ of the neurons, respectively. A small fraction of neurons (9\%) coexpressed glycine and GABA. It is apparent that the $\mathrm{GFP}^{+} \mathrm{INs}$ analyzed in our study accounted for only a small fraction of inhibitory GABA-IR CINs. This distinct subpopulation might serve a specific role in left-right coordination of locomotor rhythms.

It should be noted that GABAergic CINs could not be identified in LVIII in the cat spinal cord, indicating that contralateral inhibition is mediated primarily via glycinergic synaptic transmission (Jankowska et al., 2009). It is unknown whether the absence of homolog LVIII GABAergic CINs is related to a species difference or the age of animals studied. A developmental transition from primarily GABAergic to glycinergic neurotransmission has been reported in spinal motoneurons of newborn rats (Gao and Ziskind-Conhaim, 1995; Gao et al., 2001). Whether the GABAergic CINs characterized here transition to glycinergic phenotypes in the more mature spinal cord will need to be analyzed in more detail in future studies.

The probable function of specific groups of CINs in leftright alternating motor activity can be best analyzed by genetic deletion or silencing. Recent analyses focused on CINs derived from V0 and V3 subclasses of embryonic interneurons (for review, see Goulding, 2009; Grillner and Jessell, 2009; Kiehn et al., 2010). The majority of V0 CINs are inhibitory (70\%) (Lanuza et al., 2004), whereas most V3 CINs are excitatory (Zhang et al., 2008). Removal of V0 CINs, by deletion of cells expressing the transcription factor Dbxl, resulted in irregular periods of synchronous or alternating fictive locomotor activity between the two sides of the cord (Lanuza et al., 2004). In contrast, blocking synaptic drive from V3 excitatory CINs increased the variability of the duration of individual motor bursts and the length of the step cycles, leading to weak alternation of motor output (Zhang et al., 2008). The fact that, despite some disruption, a certain level of alternating activity is preserved suggests a redundancy in the circuitry mediating ipsilateral versus contralateral activity and perhaps the involvement of additional neuronal populations. The role of inhibitory CINs in rhythm coordination was demonstrated in a recent study analyzing netrin mutants with specific preservation of crossing excitatory $\mathrm{V} 3$ axons and deletion of most inhibitory axons (Rabe et al., 2009). In these animals, the activity in both sides of the spinal cord was obligatory synchronized, highlighting the importance of inhibition for patterning leftright alternation. Future experiments will determine which embryonic group of interneurons generates the subpopulation of GABAergic CINs described in our study, and this will hopefully open the possibility of future genetic manipulations to establish their role in the locomotor network.

In summary, we identified a subpopulation of rhythmic LVIII GABAergic commissural interneurons that established putative synaptic contacts with contralateral motoneurons and multiple groups of ventral and dorsal interneurons. We propose that, by providing rhythmic inhibitory drive to neurons with different functions, these locomotor-related inhibitory interneurons play an important role in controlling the patterns of locomotor activity in the mouse spinal cord.

\section{References}

Allain AE, Baïri A, Meyrand P, Branchereau P (2004) Ontogenic changes of the GABAergic system in the embryonic mouse spinal cord. Brain Res 1000:134-147.

Bannatyne BA, Edgley SA, Hammar I, Jankowska E, Maxwell DJ (2003) Networks of inhibitory and excitatory commissural interneurons mediating crossed reticulospinal actions. Eur J Neurosci 18:2273-2284.

Birinyi A, Viszokay K, Wéber I, Kiehn O, Antal M (2003) Synaptic targets of commissural interneurons in the lumbar spinal cord of neonatal rats. J Comp Neurol 461:429-440.

Brownstone RM, Wilson JM (2008) Strategies for delineating spinal locomotor rhythm-generating networks and the possible role of $\mathrm{Hb} 9$ interneurones in rhythmogenesis. Brain Res Rev 57:64-76.

Butera RJ Jr, Rinzel J, Smith JC (1999) Models of respiratory rhythm generation in the pre-Botzinger complex. I. Bursting pacemaker neurons. J Neurophysiol 82:382-397.

Butt SJ, Kiehn O (2003) Functional identification of interneurons responsible for left-right coordination of hindlimbs in mammals. Neuron 38:953-963.

Butt SJ, Harris-Warrick RM, Kiehn O (2002) Firing properties of identified interneuron populations in the mammalian hindlimb central pattern generator. J Neurosci 22:9961-9971.

Cangiano L, Grillner S (2003) Fast and slow locomotor burst generation in the hemispinal cord of the lamprey. J Neurophysiol 89:2931-2942.

Carlin KP, Dai Y, Jordan LM (2006) Cholinergic and serotonergic excitation of ascending commissural neurons in the thoraco-lumbar spinal cord of the neonatal mouse. J Neurophysiol 95:1278-1284.

Chang Q, Gonzalez M, Pinter MJ, Balice-Gordon RJ (1999) Gap junctional coupling and patterns of connexin expression among neonatal rat lumbar spinal motor neurons. J Neurosci 19:10813-10828.

Dai Y, Jordan LM (2010) Multiple effects of serotonin and acetylcholine on hyperpolarization-activated inward current in locomotor activity-related neurons in Cfos-EGFP mice. J Neurophysiol 104:366-381.

Dougherty KJ, Sawchuk MA, Hochman S (2009) Phenotypic diversity and expression of GABAergic inhibitory interneurons during postnatal development in lumbar spinal cord of glutamic acid decarboxylase 67-green fluorescent protein mice. Neuroscience 163:909-919.

Endo T, Kiehn O (2008) Asymmetric operation of the locomotor central pattern generator in the neonatal mouse spinal cord. J Neurophysiol 100:3043-3054

Fulton BP, Miledi R, Takahashi T (1980) Electrical synapses between motoneurons in the spinal cord of the newborn rat. Proc R Soc Lond B Biol Sci 208:115-120.

Galarreta M, Hestrin S (1999) A network of fast-spiking cells in the neocortex connected by electrical synapses. Nature 402:72-75.

Gao BX, Ziskind-Conhaim L (1995) Development of glycine- and GABA-gated currents in rat spinal motoneurons. J Neurophysiol 74:113-121.

Gao BX, Cheng G, Ziskind-Conhaim L (1998) Development of spontane- 
ous synaptic transmission in the rat spinal cord. J Neurophysiol 79: 2277-2287.

Gao BX, Stricker C, Ziskind-Conhaim L (2001) Transition from GABAergic to glycinergic synaptic transmission in newly formed spinal networks. J Neurophysiol 86:492-502.

Gibson JR, Beierlein M, Connors BW (1999) Two networks of electrically coupled inhibitory neurons in neocortex. Nature 402:75-79.

Goulding M (2009) Circuits controlling vertebrate locomotion: moving in a new direction. Nat Rev Neurosci 10:507-518.

Grillner S (2006) Biological pattern generation: the cellular and computational logic of networks in motion. Neuron 52:751-766.

Grillner S, Jessell TM (2009) Measured motion: searching for simplicity in spinal locomotor networks. Curr Opin Neurobiol 19:572-586.

Grillner S, Ekeberg, El Manira A, Lansner A, Parker D, Tegnér J, Wallén P (1998) Intrinsic function of a neuronal network: a vertebrate central pattern generator. Brain Res Brain Res Rev 26:184-197.

Hammar I, Bannatyne BA, Maxwell DJ, Edgley SA, Jankowska E (2004) The actions of monoamines and distribution of noradrenergic and serotoninergic contacts on different subpopulations of commissural interneurons in the cat spinal cord. Eur J Neurosci 19:1305-1316.

Harrison PJ, Jankowska E, Zytnicki D (1986) Lamina VIII interneurones interposed in crossed reflex pathways in the cat. J Physiol 371:147-166.

Harris-Warrick RM (2002) Voltage-sensitive ion channels in rhythmic motor systems. Curr Opin Neurobiol 12:646-651.

Heinke B, Ruscheweyh R, Forsthuber L, Wunderbaldinger G, Sandkühler J (2004) Physiological, neurochemical and morphological properties of a subgroup of GABAergic spinal lamina II neurones identified by expression of green fluorescent protein in mice. J Physiol 560: 249-266.

Hinckley CA, Ziskind-Conhaim L (2006) Electrical coupling between locomotor-related excitatory interneurons in the mammalian spinal cord. J Neurosci 26:8477-8483.

Hinckley C, Seebach B, Ziskind-Conhaim L (2005a) Distinct roles of glycinergic and GABAergic inhibition in coordinating locomotor-like rhythms in the neonatal mouse spinal cord. Neuroscience 131:745-758.

Hinckley CA, Hartley R, Wu L, Todd A, Ziskind-Conhaim L (2005b) Locomotor-like rhythms in a genetically distinct cluster of interneurons in the mammalian spinal cord. J Neurophysiol 93:1439-1449.

Hinckley CA, Wiesner EP, Mentis GZ, Titus DJ, Ziskind-Conhaim L (2010) Sensory modulation of locomotor-like membrane oscillations in Hb9expressing interneurons. J Neurophysiol 103:3407-3423.

Jankowska E (2001) Spinal interneuronal systems: identification, multifunctional character and reconfigurations in mammals. J Physiol 533: $31-40$.

Jankowska E (2008) Spinal interneuronal networks in the cat: elementary components. Brain Res Rev 57:46-55.

Jankowska E, Hammar I, Slawinska U, Maleszak K, Edgley SA (2003) Neuronal basis of crossed actions from the reticular formation on feline hindlimb motoneurons. J Neurosci 23:1867-1878.

Jankowska E, Edgley SA, Krutki P, Hammar I (2005) Functional differentiation and organization of feline midlumbar commissural interneurones. J Physiol 565:645-658.

Jankowska E, Bannatyne BA, Stecina K, Hammar I, Cabaj A, Maxwell DJ (2009) Commissural interneurons with input from group I and II muscle afferents in feline lumbar segments: neurotransmitters, projections and target cells. J Physiol 587:401-418.

Kiehn O (2006) Locomotor circuits in the mammalian spinal cord. Annu Rev Neurosci 29:279-306.

Kiehn O, Kullander K (2004) Central pattern generators deciphered by molecular genetics. Neuron 41:317-321.

Kiehn O, Dougherty KJ, Hägglund M, Borgius L, Talpalar A, Restrepo CE (2010) Probing spinal circuits controlling walking in mammals. Biochem Biophys Res Commun 396:11-18.

Lanuza GM, Gosgnach S, Pierani A, Jessell TM, Goulding M (2004) Genetic identification of spinal interneurons that coordinate left-right locomotor activity necessary for walking movements. Neuron 42:375-386.

Ma W, Behar T, Barker JL (1992) Transient expression of GABA immunoreactivity in the developing rat spinal cord. J Comp Neurol 325:271-290.

Magistretti J, Alonso A (1999) Slow voltage-dependent inactivation of a sus- tained sodium current in stellate cells of rat entorhinal cortex layer II. Ann N Y Acad Sci 868:84-87.

Mann-Metzer P, Yarom Y (1999) Electrotonic coupling interacts with intrinsic properties to generate synchronized activity in cerebellar networks of inhibitory interneurons. J Neurosci 19:3298-3306.

Matsuyama K, Nakajima K, Mori F, Aoki M, Mori S (2004) Lumbar commissural interneurons with reticulospinal inputs in the cat: morphology and discharge patterns during fictive locomotion. J Comp Neurol 474:546-561.

Matsuyama K, Kobayashi S, Aoki M (2006) Projection patterns of lamina VIII commissural neurons in the lumbar spinal cord of the adult cat: an anterograde neural tracing study. Neuroscience 140:203-218.

McCrea DA, Rybak IA (2008) Organization of mammalian locomotor rhythm and pattern generation. Brain Res Rev 57:134-146.

McLean DL, Masino MA, Koh IY, Lindquist WB, Fetcho JR (2008) Continuous shifts in the active set of spinal interneruons during changes in locomotor speed. Nat Neurosci 11:1419-1429.

Oliva AA Jr, Jiang M, Lam T, Smith KL, Swann JW (2000) Novel hippocampal interneuronal subtypes identified using transgenic mice that express green fluorescent protein in GABAergic interneurons. J Neurosci 20:3354-3368.

Parker PR, Cruikshank SJ, Connors BW (2009) Stability of electrical coupling despite massive developmental changes of intrinsic neuronal physiology. J Neurosci 29:9761-9770.

Pearson KG (1993) Common principles of motor control in vertebrates and invertebrates. Annu Rev Neurosci 16:265-297.

Phelps PE, Alijani A, Tran TS (1999) Ventrally located commissural neurons express the GABAergic phenotype in developing rat spinal cord. J Comp Neurol 409:285-298.

Puskár Z, Antal M (1997) Localization of last-order premotor interneurons in the lumbar spinal cord of rats. J Comp Neurol 389:377-389.

Quinlan KA, Kiehn O (2007) Segmental, synaptic actions of commissural interneurons in the mouse spinal cord. J Neurosci 27:6521-6530.

Raastad M, Johnson BR, Kiehn O (1997) Analysis of EPSCs and IPSCs carrying rhythmic, locomotor-related information in the isolated spinal cord of the neonatal rat. J Neurophysiol 78:1851-1859.

Rabe N, Gezelius H, Vallstedt A, Memic F, Kullander K (2009) Netrin1-dependent spinal interneuron subtypes are required for the formation of left-right alternating locomotor circuitry. J Neurosci 29:15642-15649.

Restrepo CE, Lundfald L, Szabó G, Erdélyi F, Zeilhofer HU, Glover JC, Kiehn $\mathrm{O}$ (2009) Transmitter-phenotypes of commissural interneurons in the lumbar spinal cord of newborn mice. J Comp Neurol 517:177-192.

Scheibel ME, Scheibel AB (1966) Terminal axonal patterns in cat spinal cord. I. The lateral corticospinal tract. Brain Res 2:333-350.

Seebach BS, Ziskind-Conhaim L (1994) Formation of transient inappropriate sensorimotor synapses in developing rat spinal cords. J Neurosci 14:4520-4528.

Soffe SR, Clarke JD, Roberts A (1984) Activity of commissural interneurons in spinal cord of Xenopus embryos. J Neurophysiol 51:1257-1267.

Stokke MF, Nissen UV, Glover JC, Kiehn O (2002) Projection patterns of commissural interneurons in the lumbar spinal cord of the neonatal rat. J Comp Neurol 446:349-359.

Tazerart S, Vinay L, Brocard F (2008) The persistent sodium current generates pacemaker activities in the central pattern generator for locomotion and regulates the locomotor rhythm. J Neurosci 28:8577-8589.

Tegnér J, Hellgren-Kotaleski J, Lansner A, Grillner S (1997) Low-voltageactivated calcium channels in the lamprey locomotor network: simulation and experiment. J Neurophysiol 77:1795-1812.

Tresch MC, Kiehn O (2000) Motor coordination without action potentials in the mammalian spinal cord. Nat Neurosci 3:593-599.

Walton KD, Navarrete R (1991) Postnatal changes in motoneurone electrotonic coupling studied in the in vitro rat lumbar spinal cord. J Physiol 433:283-305.

Wilson JM, Hartley R, Maxwell DJ, Todd AJ, Lieberam I, Kaltschmidt JA, Yoshida Y, Jessell TM, Brownstone RM (2005) Conditional rhythmicity of ventral spinal interneurons defined by expression of the $\mathrm{Hb} 9$ homeodomain protein. J Neurosci 25:5710-5719.

Wu L, Ziskind-Conhaim L (2006) Commissural GAD67 interneurons are constituents of rhythm-coordinating networks in the mouse spinal cord. Soc Neurosci Abstr 32:252.12. 
Zhang Y, Narayan S, Geiman E, Lanuza GM, Velasquez T, Shanks B, Akay T, Dyck J, Pearson K, Gosgnach S, Fan CM, Goulding M (2008) V3 spinal neurons establish a robust and balanced locomotor rhythm during walking. Neuron 60:84-96.

Zhong G, Díaz-Ríos M, Harris-Warrick RM (2006a) Intrinsic and functional differences among commissural interneurons during fictive locomotion and serotonergic modulation in the neonatal mouse. J Neurosci 26:6509-6517.

Zhong G, Díaz-Ríos M, Harris-Warrick RM (2006b) Serotonin modulates the properties of ascending commissural interneurons in the neonatal mouse spinal cord. J Neurophysiol 95:1545-1555.

Zhong G, Masino MA, Harris-Warrick RM (2007) Persistent sodium cur- rents participate in fictive locomotion generation in neonatal mouse spinal cord. J Neurosci 27:4507-4518.

Zhong G, Droho S, Crone SA, Dietz S, Kwan AC, Webb WW, Sharma K, Harris-Warrick RM (2010) Electrophysiological characterization of V2a interneurons and their locomotor-related activity in the neonatal mouse spinal cord. J Neurosci 30:170-182.

Ziskind-Conhaim L, Wu L, Wiesner EP (2008) Persistent sodium current contributes to induced voltage oscillations in locomotor-related hb9 interneurons in the mouse spinal cord. J Neurophysiol 100:2254-2264.

Ziskind-Conhaim L, Mentis GZ, Wiesner EP, Titus DJ (2010) Synaptic integration of rhythmogenic neurons in the locomotor circuitry: the case of Hb9 interneurons. Ann N Y Acad Sci 1198:72-84. 